Article

\title{
Temperature and Snow-Mediated Moisture Controls of Summer Photosynthetic Activity in Northern Terrestrial Ecosystems between 1982 and 2011
}

\author{
Jonathan Barichivich ${ }^{1,2, *}$, Keith R. Briffa ${ }^{1}$, Ranga Myneni ${ }^{3}$, Gerard van der Schrier ${ }^{4}$, \\ Wouter Dorigo ${ }^{5}$, Compton J. Tucker ${ }^{6}$, Timothy J. Osborn ${ }^{1}$ and Thomas M. Melvin ${ }^{1}$ \\ ${ }^{1}$ Climatic Research Unit, School of Environmental Sciences, University of East Anglia, \\ Norwich NR4 7TJ, UK; E-Mails: k.briffa@uea.ac.uk (K.R.B.); t.osborn@uea.ac.uk (T.J.O.); \\ t.m.melvin@uea.ac.uk (T.M.M.) \\ ${ }^{2}$ Laboratoire des Sciences du Climat et de l'Environnement, CEA-CNRS-UVSQ, \\ CE Orme des Merisiers, Gif sur Yvette 91191, France \\ ${ }^{3}$ Department of Geography, Boston University, Boston, MA 02215, USA; \\ E-Mail: ranga.myneni@gmail.com \\ ${ }^{4}$ Royal Netherlands Meteorological Institute, P.O. Box 201, De Bilt 3730 AE, The Netherlands; \\ E-Mail: gerard.van.der.schrier@knmi.nl \\ ${ }^{5}$ Department of Geodesy and Geoinfomation, Vienna University of Technology, Vienna 1040, Austria; \\ E-Mail: wd@ipf.tuwien.ac.at \\ ${ }^{6}$ NASA Goddard Space Flight Center, Greenbelt, MD 20771, USA; \\ E-Mail: compton.j.tucker@nasa.gov \\ * Author to whom correspondence should be addressed; E-Mail: J.Barichivich@uea.ac.uk; \\ Tel.: +44-1603-592-318; Fax: +44-1603-591-327.
}

Received: 28 December 2013 ; in revised form: 22 January 2014 / Accepted: 26 January 2014 / Published: 14 February 2014

\footnotetext{
Abstract: Recent warming has stimulated the productivity of boreal and Arctic vegetation by reducing temperature limitations. However, several studies have hypothesized that warming may have also increased moisture limitations because of intensified summer drought severity. Establishing the connections between warming and drought stress has been difficult because soil moisture observations are scarce. Here we use recently developed gridded datasets of moisture variability to investigate the links between warming and changes in available soil moisture and summer vegetation photosynthetic activity at northern latitudes $\left(>45^{\circ} \mathrm{N}\right)$ based on the Normalized Difference Vegetation Index (NDVI) since 1982. Moisture and temperature exert a significant influence on the interannual variability of
} 
summer NDVI over about 29\% (mean $r^{2}=0.29 \pm 0.16$ ) and $43 \%$ (mean $r^{2}=0.25 \pm 0.12$ ) of the northern vegetated land, respectively. Rapid summer warming since the late 1980s $\left(\sim 0.7{ }^{\circ} \mathrm{C}\right)$ has increased evapotranspiration demand and consequently summer drought severity, but contrary to earlier suggestions it has not changed the dominant climate controls of NDVI over time. Furthermore, changes in snow dynamics (accumulation and melting) appear to be more important than increased evaporative demand in controlling changes in summer soil moisture availability and NDVI in moisture-sensitive regions of the boreal forest. In boreal North America, forest NDVI declines are more consistent with reduced snowpack rather than with temperature-induced increases in evaporative demand as suggested in earlier studies. Moreover, summer NDVI variability over about $28 \%$ of the northern vegetated land is not significantly associated with moisture or temperature variability, yet most of this land shows increasing NDVI trends. These results suggest that changes in snow accumulation and melt, together with other possibly non-climatic factors are likely to play a significant role in modulating regional ecosystem responses to the projected warming and increase in evapotranspiration demand during the coming decades.

Keywords: boreal forest; snowpack; drought; soil moisture; NDVI3g; scPDSI

\section{Introduction}

Vegetation gradients and productivity patterns across the Arctic and boreal terrestrial ecosystems are interactively controlled by temperature, soil moisture, light and nutrient availability during the growing season [1-3]. Temperature is the main climate constraint on plant growth in the cooler northern regions, whilst soil moisture becomes more important toward the forest-grassland ecotone in the southern boreal region [3]. The rapid warming during recent decades has significantly ameliorated the limitations on plant production by frozen ground and low temperatures [3,4]. This has resulted in widespread lengthening of the growing season, greater photosynthetic activity and enhanced ecosystem carbon sequestration across the northern latitudes [3,5-9]. However, longer and warmer growing seasons have also promoted environmental conditions that favor surface drying [10,11]. This is thought to have intensified summer droughts, tree mortality and wildfires $[4,12,13]$.

The analysis of the global satellite record of Normalized Difference Vegetation Index (NDVI) imagery since 1981 (e.g., [14]) has shown that increases in vegetation photosynthetic activity have been stronger in Eurasia than in North America and more sustained in the colder tundra biome than over the boreal forests [15-19]. The most recent studies have found that after the initial increasing trend in NDVI (i.e., greening) observed in the first decade of the record [5,20], longer and hotter growing seasons appear to have resulted in reductions of summer NDVI (i.e., browning) in the drier and more continental regions of the boreal forest since the 1990s [15-17,21]. The most extensive vegetation browning has occurred in the North American boreal forests in Canada and Alaska [22]. Most of these regional reductions in summer NDVI have been attributed to increasing drought stress with hotter summers, an extended 
period of evaporation and enhanced atmospheric evapotranspiration demand associated with rising temperatures [15,16,21,22]. This effect is referred to as "temperature-induced drought stress" [16,23].

In a longer temporal context than the satellite period, tree-ring studies have shown that the growth of boreal trees in some cool and relatively moist northern locations has not continued to track rising temperature trends since around the 1960s, whereas they had previously shown positive responses to summer warming, such as in the early part of the 20th century [24-26]. This recent temporal change in the apparent positive response of tree growth to warming is known in the tree-ring community as the "divergence" phenomenon. A number of causal factors have been proposed and are still being debated though one suggestion is that the recent warming has invoked increasing drought stress [26]. A consistent long-term control of boreal forest growth by summer moisture availability has been observed in the drier continental interiors of Alaska and North-Western Canada where increased tree growth is stimulated by cooler and wetter growing seasons [23,27,28]. Hence, warming in these boreal regions has often been associated with tree growth declines rather than with increases [23], consistent in cases with co-located NDVI browning trends [18].

Landscape browning and declining tree-growth trends in the boreal zone have highlighted the potential role of summer drought in modulating regional responses of northern vegetation as climate warms. The emphasis of previous studies has been primarily on summer processes. The potential influence of changes in winter snowpack on summer soil moisture status and vegetation productivity has not received much attention, despite the well-known controls of snow dynamics on the hydrology and phenology of northern ecosystems [1,29,30]. Local studies have shown that reductions in winter snowpack and earlier spring snowmelt can lead to severe summer soil moisture deficits and productivity losses in boreal and alpine regions [31-33], where snow is typically the main source of soil water recharge. A positive association has also been observed between deeper snowpack and summer NDVI in central Siberia and parts of North America [34,35]. Thus, recent declines in winter snowpack and snow cover duration documented in several regions of northern Eurasia and North America [36-38] are likely to have affected ecosystem function.

The lack of long-term soil moisture observations and uncertainties in model-based soil moisture estimates have hampered assessments of the links between trends in vegetation productivity and changes in soil moisture availability in the northern latitudes. Local and regional responses of boreal vegetation to moisture variability have typically been inferred indirectly from correlations with soil moisture forcings, such as precipitation and temperature (e.g., $[23,39,40]$ ). In other cases, comparisons have been made with simple meteorological drought indices that often neglect soil properties, snow dynamics and vegetation (e.g., [21,35,41]).

The historical paucity of observational datasets of soil moisture dynamics has been notably improved by the recent release of a multi-satellite product of surface soil moisture with global coverage for the period 1979-2010 [42] and an improved high-resolution global dataset of the self-calibrating Palmer Drought Severity Index (scPDSI) based on historical monthly meteorological observations since 1901 [43]. Progress has also been made in producing improved estimates of seasonal snow mass dynamics by assimilating ground-based measurements with historical satellite observations within a consistent modeling framework [44]. Moreover, the reprocessing of the NDVI observations from Advanced Very High Resolution Radiometer (AVHRR) satellite sensors by the Global Inventory 
Modeling and Mapping Studies (GIMMS) group at NASA Goddard Space Flight Center has resulted in a 30-year NDVI product with improved data quality at northern latitudes ([45]). These new datasets enable a more direct and up-to-date assessment of the multi-decadal links between warming, snow, soil moisture variability and vegetation dynamics in the northern latitudes than was previously possible.

Here we use these newly released datasets, firstly to assess the evidence for changes in drought severity with recent warming and secondly to evaluate the influence of temperature, snowpack and soil moisture availability on peak summer NDVI in northern terrestrial ecosystems between 1982 and 2011. The results of this empirical study provide a better understanding of the environmental drivers of interannual and longer term changes in vegetation productivity at northern latitudes.

\section{Data and Methods}

\subsection{Northern Biomes}

The study domain was divided into three major biogeographic regions: northern temperate, boreal and Arctic. The regions were defined from the Collection 5 MODIS International Geosphere-Biosphere Programme (IGBP) land cover classification map [46] and woody fraction from the MODIS Vegetation Continuous Fields product [47]. The first region includes the northern temperate grasslands, croplands and a small fraction of temperate forests, the second considers only the boreal forests, and the third includes the Arctic tundra and subarctic woodlands.

The boreal forest region was defined as all evergreen needleleaf, deciduous needleleaf and mixed forests north of $45^{\circ} \mathrm{N}$ with woody fraction greater than $30 \%$ [19]. Natural grasslands, crops and relatively small areas of temperate forests north of $45^{\circ} \mathrm{N}$ and south of the boreal forests were considered as the northern temperate grassland and cropland region. Open woodlands (forests with woody fraction less than $30 \%$ ), open/closed shrublands and grasslands north of the boreal forests were combined into a large mixed region, termed here Arctic region, since the NDVI signal in these land cover classes is dominated by shrubby and herbaceous vegetation. These major regions delineate circumpolar bands of relatively similar vegetation types and climate conditions (Figure A1).

\subsection{Quantifying Changes in Summer Drought and the Influence of Evapotranspiration Demand}

An enhanced version of a recently released global gridded dataset of monthly scPDSI for the period 1901-2009 [43] was used as the basis for investigating long-term changes in drought severity in the study domain. This dataset has several methodological improvements that allow a better quantification of drought at northern latitudes. First, the more physically-based Penman-Monteith (PM) parameterization for potential evapotranspiration (PET) is used instead of the simple temperature-dependent Thornthwaite (TH) approach. Second, the actual vegetation cover rather than a fixed simple reference crop is used for computing potential evapotranspiration. Third, seasonal snowpack dynamics are considered in the water balance model.

The consideration of snow in the soil water balance is essential for achieving a more realistic estimate of seasonal soil moisture variability in the snow-dominated northern latitudes. The realism of the snow parametrization was corroborated by significant correlations between monthly anomalies in terrestrial 
water storage from GRACE satellites and the sum of monthly estimates of snow water equivalent (SWE) and soil moisture storage in the scPDSI [43]. Other factors that could have an effect on soil moisture availability in the northern latitudes, such as permafrost dynamics, vegetation phenology and the influence of increasing atmospheric concentration of carbon dioxide on plant transpiration are not accounted for in the surface water balance of the scPDSI.

The original version of the scPDSI dataset (CRU-scPDSI) is based on the CRUTS 3.10.01 meteorological fields (precipitation for water supply; temperature, cloud cover, vapor pressure and wind for PM PET) produced by the Climatic Research Unit at $0.5^{\circ}$ spatial resolution [48]. Since about 1996 the CRUTS 3.10.01 precipitation data are slightly "wetter" at northern latitudes than other precipitation products that are based on many more rain gauge data (see Figure A2) [49]. For this reason, we have recomputed the scPDSI dataset using precipitation data from the GPCC Full Data Reanalysis version 6 at $0.5^{\circ}$ resolution instead [50]. The GPCC dataset currently incorporates the largest number of rain gauge series [49]. Inevitably most of the gauge data incorporated in any global precipitation dataset represent the more populated regions, south of the Arctic circle (Figure A2). North of $60^{\circ} \mathrm{N}$, the number of rain gauges in the GPCC product drops from a maximum of 1,374 in the late 1980s to about 300 in 2010, whilst CRUTS 3.10.01 has a maximum of only 300 gauges, falling to less than 120 after 1995. Prior to 1936 , both products use less than 180 gauge records. Using the GPCC product to drive the scPDSI algorithm reduces uncertainties in regional precipitation estimates during recent decades, but not in the first half of the 20th century (Figure A2). Therefore, we have restricted our analysis of the scPDSI to the period 1950-2009.

To isolate the potential influence of increased evapotranspiration demand on drought severity due to climate change, the scPDSI was computed with two different PET implementations: actual monthly PET and fixed climatological monthly PET based on the climatology for the period 1961-1990. In the latter setup, fixed climatological temperature data were also used to drive the snow model. Therefore, the differences between the two analyses represent the influence of changes in atmospheric evapotranspiration demand and temperature-driven snow melt on drought severity, though the effect of the latter may be small due to the coarse monthly resolution of the data.

Monthly surface soil moisture data (0-10 cm depth) simulated by the Noah land surface model [51] were obtained from the latest version of the Global Land Data Assimilation System (GLDAS-2, http://ldas.gsfc.nasa.gov/gldas/) to asses the reliability of the scPDSI as a proxy for soil moisture variability in each biogeographic region.

\subsection{Vegetation Photosynthetic Activity}

The NDVI is a spectral measure of the photosynthetic potential of green vegetation [52], which is commonly referred to as vegetation photosynthetic activity or greenness. The latest version of the 15-day GIMMS NDVI dataset (NDVI3g) developed by the GIMMS group at NASA Goddard Space Flight Center (see [45]) was used to characterise interannual variations in summer vegetation photosynthetic activity across the region north of $45^{\circ} \mathrm{N}$ between 1982 and 2011 (Table 1). The 8-km biweekly NDVI data for each year and grid box were seasonally averaged over the summer months from June to August, when the peak in growing season photosynthetic activity occurs. To avoid the effect of snow on NDVI 
averages in some small far north Arctic regions and exclude sparsely vegetated areas from the analysis, only biweekly NDVI values greater than 0.1 were used for averaging. Product quality flags indicated that during June only $1.8 \%$ of the $8-\mathrm{km}$ grid boxes in the study domain have more than a quarter of the sixty biweekly NDVI composites estimated from the mean seasonal NDVI profile because of snow cover. In July and August, this is less than $0.2 \%$ of the grid boxes. Retaining NDVI values greater than 0.1 effectively removes these few lower quality NDVI estimates. The snow-free mean summer NDVI data were then regridded to a common $0.5^{\circ} \times 0.5^{\circ}$ regular grid using bilinear interpolation. This enables direct grid-wise comparisons with climate and moisture fields (Table 1).

NDVI data based on the 16-day Aqua MODIS MYD13C1 product [53] were used for independent validation of the peak growing season vegetation signals contained in the NDVI3g dataset during the overlapping period 2003-2011. The 16-day NDVI composites were averaged for summer months and regridded from their native $0.05^{\circ}$ resolution to $0.5^{\circ}$. MODIS NDVI data are of higher radiometric, spatial and geometric quality than AVHRR data and have been explicitly atmospherically corrected and masked for water, clouds and shadows. We chose Aqua rather than Terra MODIS NDVI because the Terra NDVI data are affected by sensor degradation, imposing spurious negative trends in the dataset [54].

Table 1. Characteristics of the datasets used in this study.

\begin{tabular}{|c|c|c|c|}
\hline Dataset & Resolution & Time Span & Reference \\
\hline \multicolumn{4}{|l|}{ Vegetation } \\
\hline GIMMS NDVI3g & $0.08^{\circ} \times 0.08^{\circ}, 15$-day & 1982-2011 & Pinzon and Tucker [45] \\
\hline Aqua MODIS NDVI (MYD13C2) & $0.05^{\circ} \times 0.05^{\circ}, 16$-day & 2002-2011 & Huete et al. [53] \\
\hline \multicolumn{4}{|l|}{ Temperature } \\
\hline CRUTS 3.20 mean air temperature & $0.5^{\circ} \times 0.5^{\circ}$, monthly & 1901-2011 & Harris et al. [48] \\
\hline \multicolumn{4}{|l|}{ Precipitation } \\
\hline GPCC precipitation version 6 & $0.5^{\circ} \times 0.5^{\circ}$, monthly & $1901-2010$ & Schneider et al. [50] \\
\hline Globsnow SWE version 1.3 & $25 \times 25 \mathrm{~km}$, monthly & 1980-2011 & Takala et al. [44] \\
\hline \multicolumn{4}{|l|}{ Soil moisture } \\
\hline Satellite microwave soil moisture (MW-SMO) & $0.25^{\circ} \times 0.25^{\circ}$, daily & 1979-2010 & Liu et al. [42] \\
\hline Self-calibrating PDSI (scPDSI) & $0.5^{\circ} \times 0.5^{\circ}$, monthly & $1901-2009$ & van der Schrier et al. [43] \\
\hline GLDAS-2 Noah 10-cm soil moisture & $1^{\circ} \times 1^{\circ}$, monthly & $1948-2007$ & Rui $[51]$ \\
\hline
\end{tabular}

\subsection{Influence of Snow, Moisture and Temperature Variability on Summer NDVI}

Temperature and moisture controls of interannual variability in summer vegetation photosynthetic activity since 1982 were identified using correlation and stepwise multiple linear regression analyses involving summer NDVI and spring and summer averages of temperature and moisture variables at a $0.5^{\circ}$ grid box scale (Table 1). Mean air temperature data for the period 1982-2011 were obtained from the gridded CRUTS 3.20 dataset at a spatial resolution of $0.5^{\circ}$ [48]. Spring water supply to the soils was estimated using maximum monthly winter/spring Snow Water Equivalent (SWE) during the period 1982-2011, computed from monthly gridded SWE data from the European Space Agency (ESA) GlobSnow dataset version 1.3 [44]. GlobSnow combines SWE retrieved from multi-satellite microwave observations with forward snow emission model simulations and ground-based weather station data for non-mountainous regions of the Northern Hemisphere. Because of the improved accuracy achieved by assimilating independent sources of information, this is the best SWE product currently available for 
climate analysis [55]. The SWE data were remapped from their original $25-\mathrm{km}$ spatial resolution to a coarser $0.5^{\circ}$ grid using bilinear interpolation. Summer precipitation data during the period 1982-2010 were obtained from the gauge-based Global Precipitation Climatology Center (GPCC) dataset at a spatial resolution of $0.5^{\circ}[50]$.

Spring and summer averages of scPDSI were used to characterise soil moisture variability between 1982 and 2009. In addition, satellite microwave soil moisture observations (MW-SMO) from a newly developed global dataset [42]) were also used to estimate summer surface soil moisture variability during the period 1982-2010. This soil moisture dataset is based on the statistical blending of daily passive and active satellite microwave observations between November 1978 and December 2010 on a $0.25^{\circ} \times 0.25^{\circ}$ regular grid. Although satellite sensors only measure moisture in the uppermost few centimeters of the soil profile, these observations generally correlate with moisture variations measured at deeper layers [56]. Soil moisture retrievals fail over very dense canopy and frozen ground while surface water and rough topography distort soil moisture signals and result in poor data quality. Product quality flags were used to filter daily observations for most of these surface conditions. The data were remapped to the common $0.5^{\circ}$ grid resolution using bilinear interpolation and only grid boxes with at least 20 years of data over the period 1982-2010 were used for analysis.

In order to examine the relationships on an interannual time scale, all time series at each grid box were linearly detrended prior to correlation and regression analysis. The statistical significance of correlations was estimated using a non-parametric random phase test with 1,000 Monte-Carlo simulations [57], and a $90 \%$ confidence level was used to report the significance of the correlations. In the stepwise regression models, only temperature and moisture predictors of summer NDVI significant at the $90 \%$ confidence level were retained.

Since earlier studies have reported changes in the climate drivers of NDVI with recent climatic warming [4,21], we also empirically tested for temporal changes in the association between interannual summer NDVI variability and each temperature and moisture variable at each grid box using a statistical approach based on time-varying regression with the Kalman Filter [58]. This method allows for the estimation of simple linear regression models with time-varying coefficients that adapt to the changing relationship between the predictor (moisture or temperature) and the predict and (NDVI). A maximum likelihood estimation procedure is used to obtain the regression coefficients and associated standard errors to assess their significance over time. In order to restrict the analysis to interannual time scales, all the variables were filtered with a 10-year high-pass filter prior to analysis. The Akaike Information Criterion (AIC) was used to evaluate whether the dynamic Kalman filter regression model had a better explanatory power than a simple time-invariant least squares linear regression model in each grid box.

After characterizing the temperature and moisture controls of summer photosynthetic activity on interannual time scales, the consistency between temporal trends in summer NDVI and temperature and moisture controls was evaluated. In this context, warming trends are expected to correspond well with greening trends in temperature-limited regions whilst drying trends should correspond with browning trends in moisture-limited regions. Trend analysis was carried out using the non-parametric Mann-Kendall trend test implemented in the zyp package [59] in R statistics. Maximum Covariance Analysis (MCA), also known as Singular Value Decomposition, was employed to describe the dominant patterns of coupled variability between climate factors and summer NDVI in the boreal and Arctic 
regions of North America. This is a statistical tool widely used in climate research to identify coupled modes in pairs of spatiotemporal geophysical fields [60]. Because MCA finds signals that are common in the two fields, stochastic noise from fire and other local-scale disturbances that could only affect the NDVI does not affect the results.

\section{Results}

\subsection{Summer Moisture Variability since 1950 and the Influence of Evapotranspiration Demand}

Figure 1a compares the yearly time series of the percentage of land area north of $45^{\circ} \mathrm{N}$ that is dry in summer ( scPDSI $\leq-2$ ), based on the scPDSI with fixed and actual PET. The difference between the series reflects the influence of changing PET on summer drought severity. The series are very similar prior to the start of the surface warming trend around 1988. Both series show a strong decrease in dry area from about $25 \%$ to around $12 \%$ during the 1950 s and values ranging between $9 \%$ and $22 \%$ thereafter. After 1988, the series consistently diverge along with the rapid surface warming, indicating an increasing influence of evaporative demand on summer drought severity during this period. Without the inferred increase in evaporative demand, the northern latitudes would have experienced a downward trend in drought severity. Although the increase in PET since the 1980s has not resulted in a clear increasing trend in drought severity, it has offset the effect of the concurrent increase in increasing precipitation at high latitudes (Figure A2).

Greater evaporative demand since the 1980s has also consistently impacted the summer wet area (with scPDSI $\geq 2$ ) in the northern latitudes (Figure 1b). Unlike the case for summer dry area, the effect appears to have been greater since around 1997, when summer temperatures further increased to a new level. The 2000s is the decade with the warmest and wettest summers since 1950. The wettest summer in the record is 2007 , with nearly $32 \%$ of the area under moderately wet conditions when considering actual PET and about $35 \%$ when holding PET constant. This is more than $12 \%$ higher than the long-term average of summer wet area (about 20\%).

The effect of recent increases in PET on the scPDSI over each region and continent is illustrated in Figure 2. In general, the influence of PET on the scPDSI mirrors the magnitude of surface warming and has been larger in Eurasia than in North America. The circumpolar Arctic region has experienced the fastest warming rates and the greatest effect of increasing PET on summer drought severity since around 1988. Warming related increases in PET have also influenced drought severity in the boreal forests and temperate grasslands and croplands, but only in Eurasia and since around 1997. In North America, these regions have experienced little or no warming, limiting the PET influence on summer drought severity in recent decades. Similar regional effects of increased evapotranspiration on drought severity occur during the period of spring snowmelt (April-May), but unlike in summer the magnitude is not sufficiently strong to offset the circumpolar wetting trend (Figure A3). These results suggest that the severe regional droughts in boreal and temperate North America during recent years (e.g., 2001-2003) have been driven by precipitation deficits, whilst ongoing warming in far northern North America and boreal and temperate Eurasia has amplified the severity and extent of droughts during the past one to two decades. 
Figure 1. Temporal variability in percentages of summer dry and wet areas in the northern latitudes $\left(>45^{\circ} \mathrm{N}\right)$ between 1950 and 2009 based on the scPDSI computed with (red) and without (blue) interannual changes in potential evapotranspiration (PET). (a) dry area (summer scPDSI $\leq-2$ ); (b) wet area (summer scPDSI $\geq 2$ ). Also shown are the mean summer temperature anomalies for the region (gray dotted line) and the long-term mean of the percentage area series based on actual PET (red dashed line).
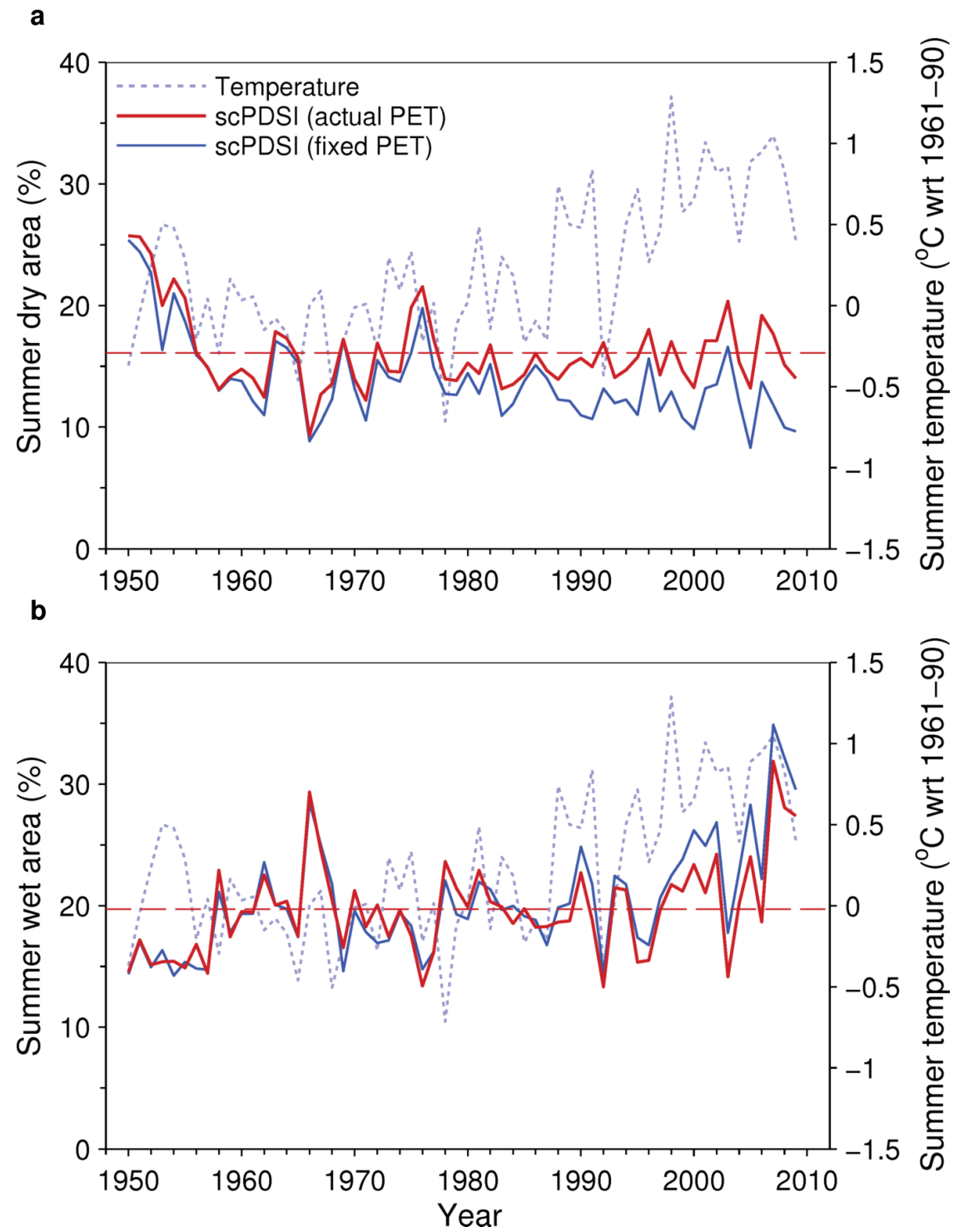

Regional and continental averages of summer scPDSI calculated using actual PET are significantly correlated with the corresponding averages of summer surface soil moisture (down to $10 \mathrm{~cm}$ ) simulated by the Noah GLDAS-2 land surface model over the period 1948-2008 (Figure A4). This shows that normalised moisture anomalies based on the scPDSI are consistent with simulations by more complex land surface models forced with different observations. However, the relationship is generally poor in the earlier period before about 1970 but thereafter the datasets agree very well. The contrasting agreement between these two periods is consistent with larger uncertainties in the underlying meteorological forcings during the earlier period. 
Figure 2. Comparison by region and continent between summer scPDSI averages with (red) and without (blue) interannual changes in potential evapotranspiration (PET). Mean summer temperature anomalies relative to the period 1961-1990 (dotted line) are shown for each biome. The red crosses in each panel indicate values of the average scPDSI series with actual PET within the bottom 20th percentile, which can be thought as regional summer droughts. Note that the severity of most of these drought events occurring during the warming period over the last two decades has been intensified by increasing evapotranspiration demand. The vertical dotted lines denote the years 1988 or 1997.
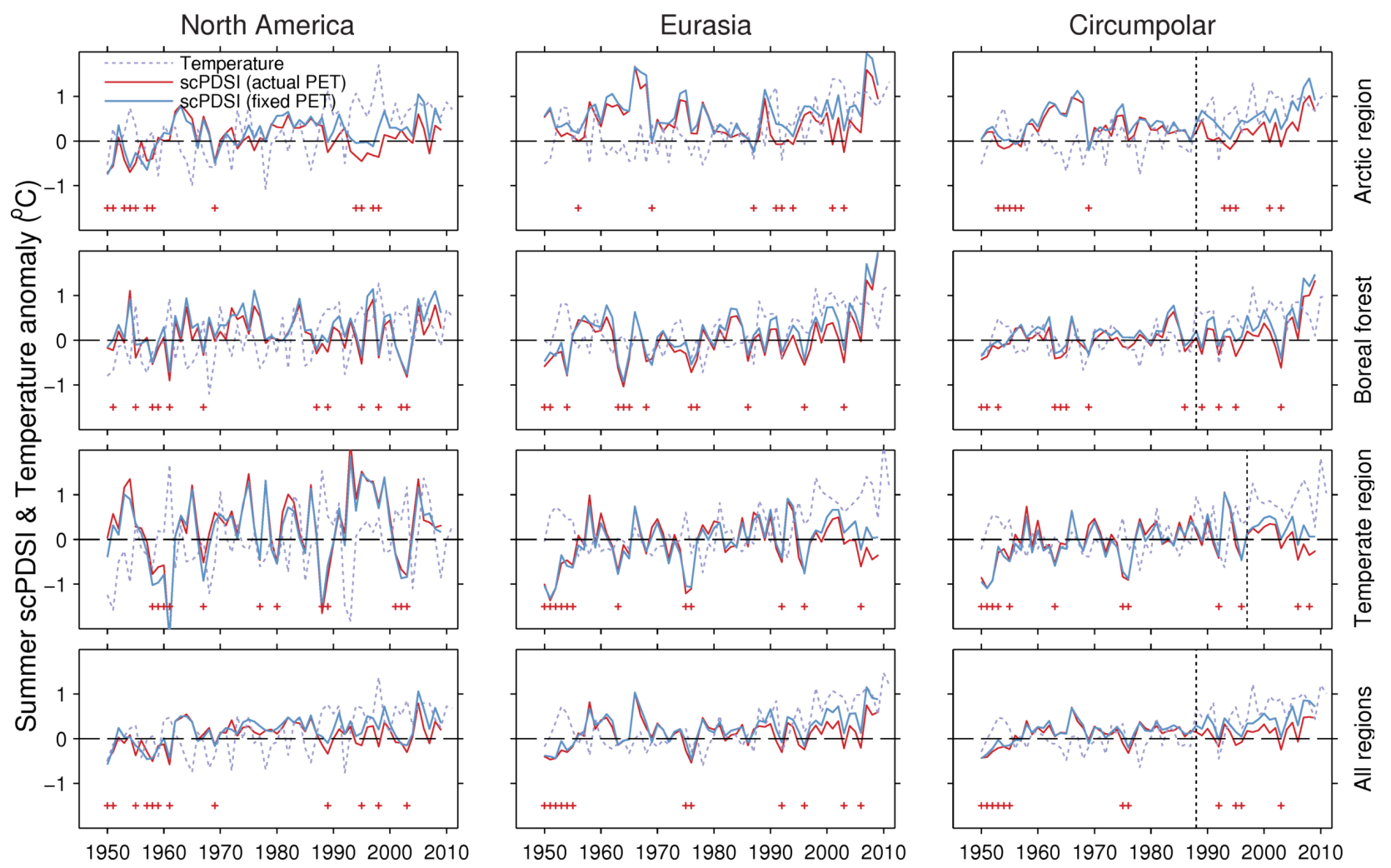

\subsection{Moisture and Temperature Controls on Interannual Summer NDVI Variability}

\subsubsection{Correlations}

Summer NDVI3g during the period 2003-2011 is consistent with Aqua-MODIS NDVI over most of the northern terrestrial ecosystems (Figure A5). The agreement between the NDVI products is particularly strong in North America, with significant $(p<0.1)$ correlation values ranging from 0.80 in the boreal forests to 0.85 in the Arctic region and 0.94 in the temperate grasslands and croplands. The lowest agreement occurs over the vast Eurasian grasslands and croplands $(r=0.38, p>0.1)$, but the products agree better in the boreal forests $(r=0.63, p>0.1)$ and in the Arctic region of Eurasia $(r=0.80, p<0.1)$. This demonstrates that both datasets capture similar vegetation signals at high latitudes. 
Figure 3. Correlation maps between summer NDVI and summer temperature, water supply and soil moisture variability since 1982. (a) Summer air temperature; (b) Summer precipitation; (c) Summer scPDSI; (d) Summer satellite microwave surface soil moisture (MW-SMO). All correlations are based on linearly detrended data and the stippling indicates statistically significant $(p<0.1)$ values.
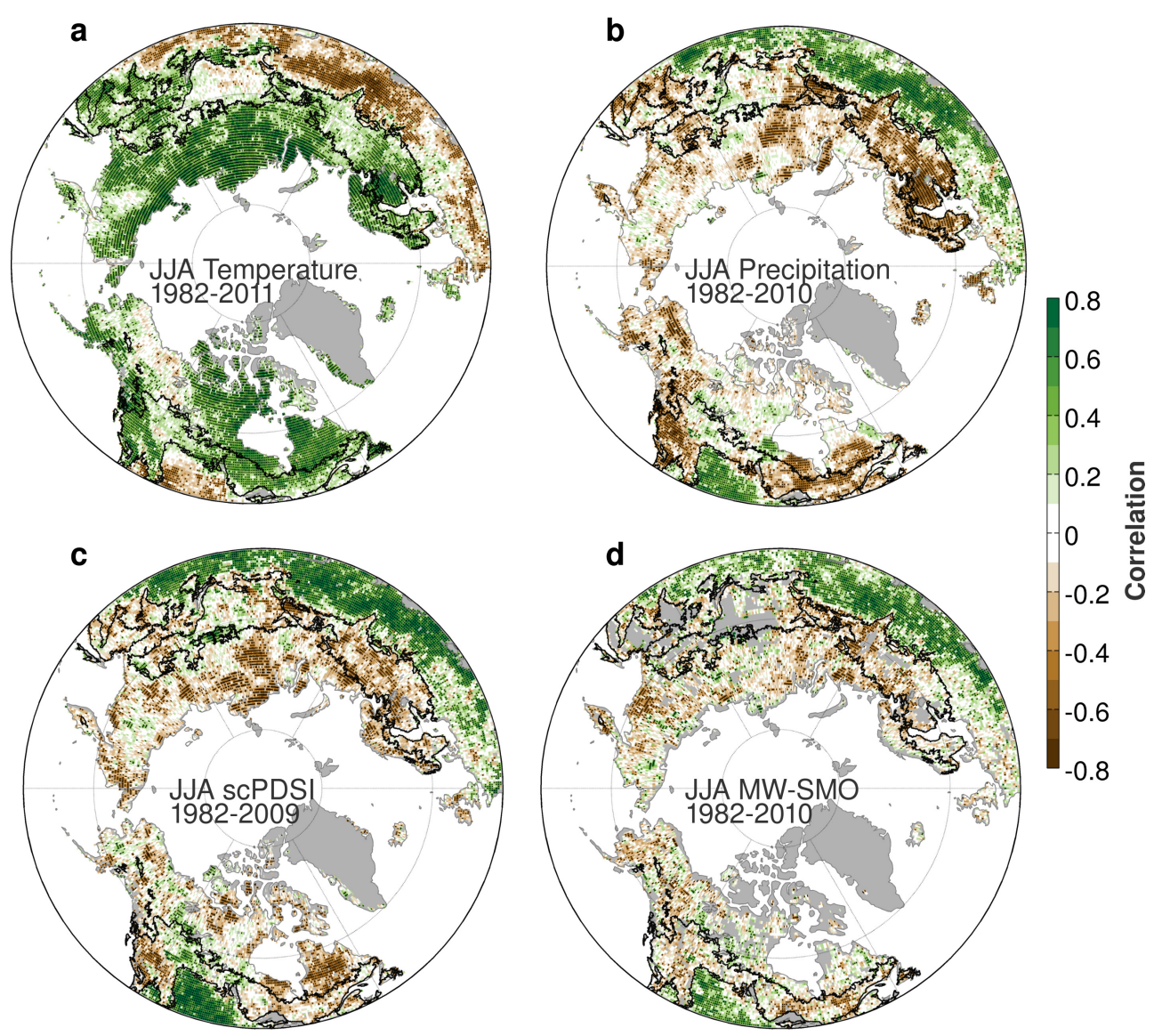

It is expected that interannual variability in summer NDVI is associated with moisture variability in the northern temperate grasslands and croplands and with temperature variability in the cooler regions dominated by boreal forests and Arctic vegetation. This expectation is broadly consistent with the biome-scale spatial patterns of correlation between interannual anomalies of summer NDVI and concurrent variability in summer temperature, precipitation and available soil moisture shown in Figure 3. Summer NDVI across most of the Arctic and boreal regions is strongly positively correlated with summer temperature (Figure 3a), but it is generally negatively correlated with summer precipitation and soil moisture anomalies as indicated by the scPDSI and satellite-sensed MW-SMO (Figure 3b-d). This negative correlation of temperature-driven summer NDVI with summer precipitation and soil moisture anomalies largely reflects a strong negative association between summer temperature and precipitation in these regions (Figure A6a). However, it might also indicate a degree of co-limitation by low radiation levels during rainy and cloudy summers. The opposite correlation patterns occur in the northern temperate grasslands and croplands, where summer NDVI is negatively correlated with temperature and strongly positively correlated with precipitation and soil moisture anomalies during summer. Overall, these broad-scale summer correlation patterns suggest a dominant temperature control 
on peak vegetation photosynthetic activity in the boreal and Arctic regions and a moisture control in the temperate grasslands and to a lesser extent in croplands.

There are, however, large areas within the cool boreal and Arctic regions where correlation patterns suggest that moisture rather than temperature is the main control of summer NDVI anomalies, especially when considering the influence of snow water supply (Figures 3 and 4). This moisture control is apparent across most of the rainshadow area of the North American Cordillera along the western interior of Canada from the Prairies in the south to interior Alaska and the Arctic coast in the north, the basin of the Kolyma River in far-east Siberia and in some isolated areas north of Lake Baikal in south-central Siberia. Summer NDVI in these regions is not significantly correlated with temperature variability during summer (Figure 3a) or spring (Figure 4a), but it is generally significantly and positively correlated with summer precipitation, scPDSI and MW-SMO (Figure 3b-d). The influence of moisture on summer photosynthetic activity in these cool regions is more spatially extensive when considering the effect of snow. Maximum SWE and spring scPDSI are both strongly correlated with summer NDVI in the sense that deeper winter snowpacks and hence wetter spring soils enhance summer NDVI (Figure 4b,c). Therefore, the water supplied by the melting of the winter snowpack in spring appears to play the dominant role in modulating subsequent summer photosynthetic activity of northern vegetation in these relatively cold but moisture limited regions. Only few temperature-limited regions show negative associations between summer NDVI and maximum SWE, highlighting the beneficial effect of snow accumulation on peak summer vegetation growth.

Figure 4. Correlation maps between summer NDVI and spring (March-May) temperature, snow water supply and soil moisture variability since 1982. (a) Spring air temperature; (b) Maximum Snow Water Equivalent (SWE); (c) Spring scPDSI. All correlations are based on linearly detrended data and the stippling indicates statistically significant $(p<0.1)$ values.
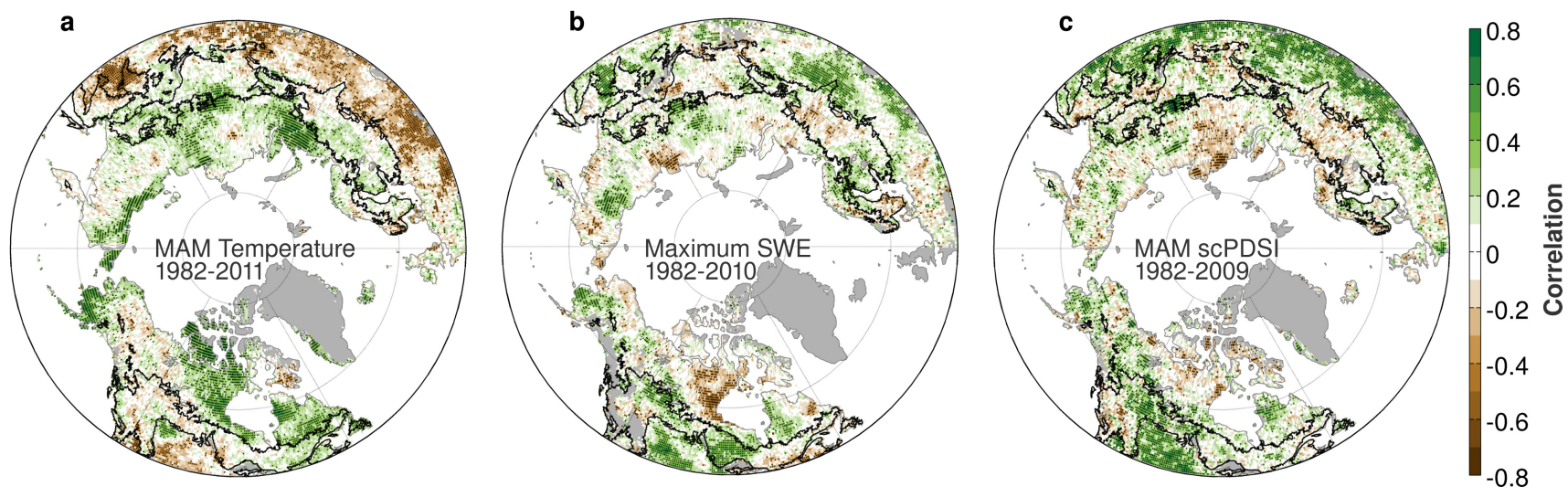

Snow-water supply and associated spring soil moisture anomalies (scPDSI) also significantly influence summer photosynthetic activity in some typically moisture-limited regions, such as the Canadian Prairies and the vast steppes of central Asia (Figure 4b,c). Moreover, spring temperatures in these more southern regions are negatively correlated with summer NDVI (Figure 4a), implying that earlier and warmer springs favor surface drying and hence can reduce summer photosynthetic activity if summer rainfall does not replenish moisture losses. 
A more synthetic depiction of the geography of moisture and temperature limitations on peak summer photosynthetic activity can be obtained by superposing the patterns of correlation of summer NDVI with summer temperature and scPDSI averaged over the spring-summer period from March to August. A bivariate map showing these associations together with their statistical significance and a detailed land cover classification map are illustrated in Figure 5. The composite map reveals a consistent pattern of climate control on peak summer photosynthetic activity across northern biomes but it highlights important regional variations in the type and magnitude of climate limitation. The forest/grassland ecotone in central Asia and Canada marks a sharp transition between temperature limitation (i.e., strong and positive correlations with temperature and weak correlations with scPDSI) in the boreal forests and Arctic shrublands and tundra towards the north and moisture limitation (i.e., positive and strong correlations with scPDSI and negative correlations with temperature) in the temperate grasslands and croplands to the south (Figure 5a).

The composite map also highlights the extensive area of the boreal and Arctic regions with significant moisture sensitivity along the drier western interior of North America. Vegetation in this region varies from dense evergreen needleleaf forests in the central boreal region to sparsely forested woody savanna and open shrublands toward the north (Figure 5b). Other, more localized, high-latitude areas of moisture sensitivity are also evident in sparsely forested areas near the treeline in the basin of the Kolyma River and in deciduous needleleaf forests north of Lake Baikal. However, the magnitude of moisture limitation in all of these northern regions is typically smaller and less spatially coherent than that in the adjacent regions where growth is limited by temperature. There are also extensive parts of the mixed and evergreen needleleaf boreal forests in central Eurasia where neither temperature nor soil moisture appear to limit peak forest photosynthetic activity significantly during the seasonal windows considered here. The same is true for the shrublands north of the treeline in the far east of Eurasia and northern Alaska, and most of the European croplands and mixed forests in eastern North America. It is interesting that a similar pattern of regional and broad-scale climate limitation of summer photosynthetic activity is obtained from correlations computed over the past decade (instead of the entire period) and from Aqua-MODIS NDVI data between 2003 and 2009 (Figure A7).

It is also noteworthy that summer scPDSI and MW-SMO are both similarly correlated with summer NDVI (Figure 3c,d), with a common spatial pattern that strongly resembles the pattern of correlations observed between NDVI and summer precipitation (Figure 3b). This high commonality between MW-SMO and scPDSI is linked to the common summer precipitation signal in these products. Summer MW-SMO variability is similarly correlated with summer precipitation and scPDSI anomalies, but the agreement is stronger in the northern temperate region than in the boreal and Arctic regions where satellite retrievals are less reliable due to canopy interference and surface water (Figure A6b,d). Likewise, the influence of snowmelt water on spring scPDSI leads to similar correlation patterns between summer NDVI and maximum SWE and spring scPDSI over most of the snow-dominated regions (Figure $4 \mathrm{~b}, \mathrm{c}$ ). The only exceptions are in western Russia and Scandinavia, where maximum SWE tends to be negatively correlated with spring scPDSI (Figure A6c). 
Figure 5. Geography of moisture and temperature controls on summer NDVI at northern latitudes during the last 30 years and relationship with major land cover types. (a) Bivariate correlation map between detrended summer (June-August) NDVI and detrended variations in spring-summer (March-August) scPDSI and summer temperature during the period 1982-2009. Light greens indicate a strong moisture limitation (i.e., strong positive correlation with precipitation and negative correlation with temperature), whilst purple shades indicate a dominant temperature limitation (i.e., strong positive correlation with temperature and weak correlation with precipitation). The stippling indicates grid boxes where either correlations with temperature or scPDSI are statistically significant $(p<0.1)$; (b) IGBP land cover classification for the study domain. The black polygons in the maps denote the extent of the boreal forests as defined in this study. Also shown is the present position of the latitudinal treeline (purple line).
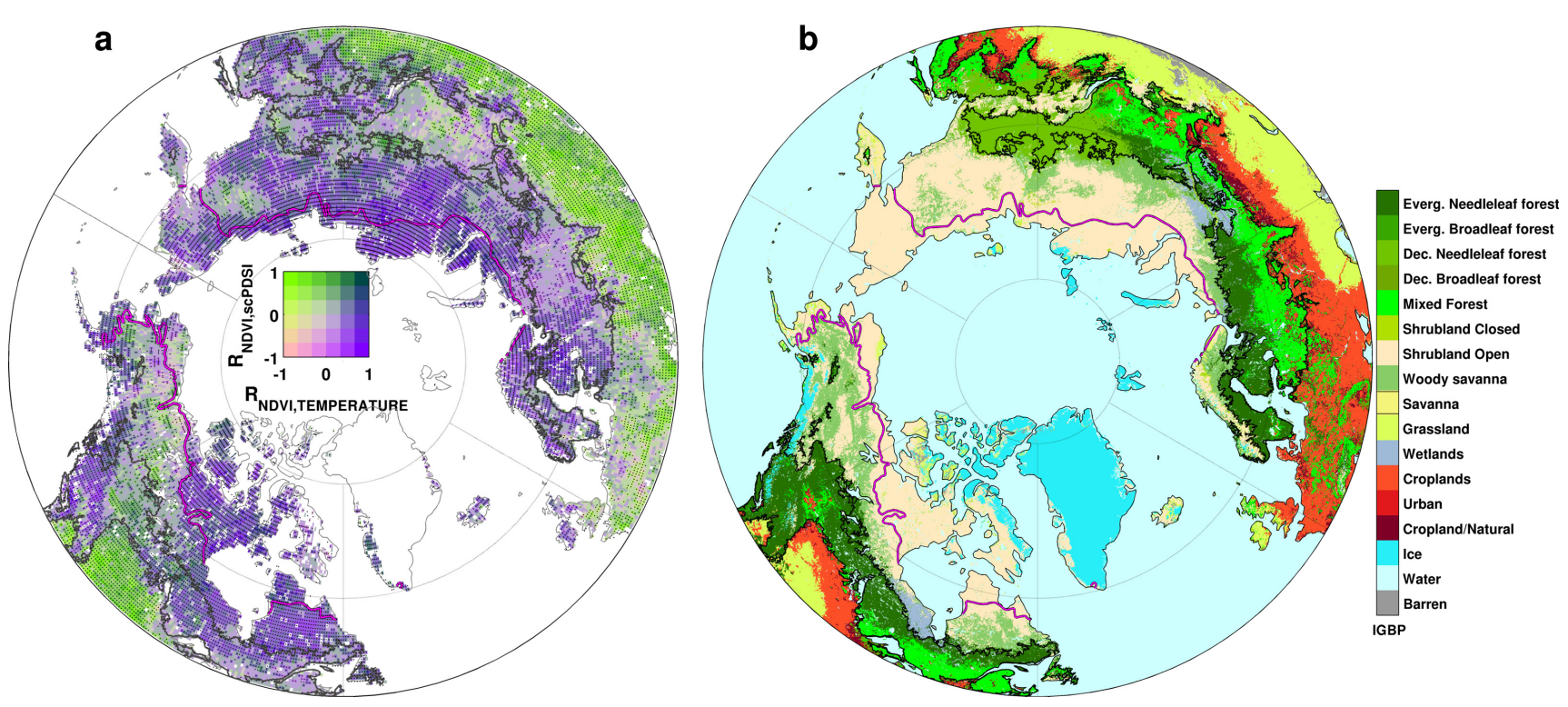

\subsubsection{Stepwise Regression}

The correlations show that changes in summer precipitation or summer soil moisture alone are not sufficient to fully capture the moisture signal in summer vegetation photosynthetic activity in the boreal and Arctic regions. Snowmelt water and the associated spring soil moisture anomalies must also be taken into account. Stepwise multiple linear regression shows that the combined influence of either spring and summer water supply or soil moisture accounts for up to $20 \%-30 \%$ of the total interannual variance in summer NDVI in the moisture-sensitive areas of the boreal forest and Arctic regions (Figure 6a,b). This amount of variance is small compared with the predominant influence of spring and summer temperature, which typically explains between $30 \%$ and more than $50 \%$ of the total variance in summer NDVI in the coldest parts of these northern biomes, such as north-eastern Canada, Siberia and Scandinavia (Figure 6c). The largest area of the circumpolar boreal forests that exhibits a consistent moisture limitation occurs in the dense needleleaf forests of the continental interior of North America. As noted earlier, this region displays practically no temperature signal and extends northwards 
into the Arctic region through the rainshadow area of the North American Cordillera as far north as the interior of Alaska (Figure 6b,c).

Figure 6. Fraction of interannual summer NDVI variance explained by spring (March-May) and summer water supply, soil moisture and temperature during the period 1982-2009. The maps show the $R^{2}$ for a stepwise multiple linear regression model predicting summer NDVI at each grid box based on: (a) water supply ( $x_{1}=$ peak SWE, $x_{2}=$ summer precipitation); (b) soil moisture ( $x_{1}=$ spring scPDSI, $x_{2}=$ summer scPDSI); (c) temperature $\left(x_{1}=\right.$ spring temperature, $x_{2}=$ summer temperature $)$; and (d) soil moisture and temperature $\left(x_{1}=\right.$ spring scPDSI, $x_{2}=$ summer scPDSI, $x_{3}=$ spring temperature, $x_{4}=$ summer temperature). All the variables were linearly detrended prior to analysis and only predictors significant at the $90 \%$ confidence level were retained in the regression models. Only positive associations between summer NDVI and variables representing water supply and soil moisture were considered. The stippling in $\mathbf{c}$ indicates grid boxes where NDVI is inversely associated with temperature. Gray shading denotes non-vegetated areas or areas where climate data were not available.
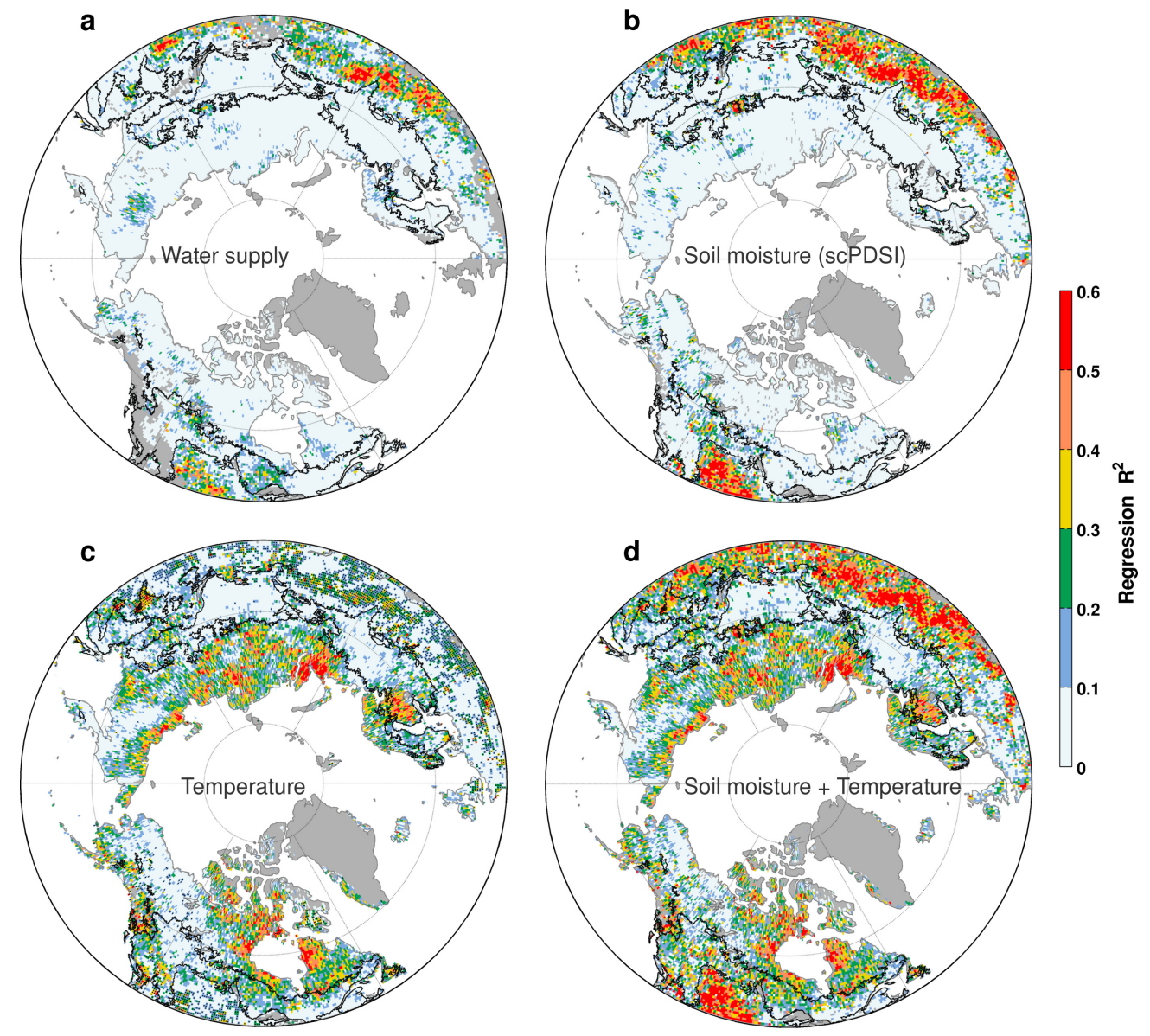

In moisture limited regions where grasses are the dominant vegetation type, such as the steppes of central Asia and the Canadian prairies, precipitation and soil moisture typically account for more than $50 \%$ of the interannual variance in NDVI (Figure 6a,b), though the influence of soil moisture is consistently stronger and more spatially extensive than that of precipitation. Locally negative associations between temperature and NDVI in these water-limited regions can account for up to about 
$30 \%$ of the total NDVI variance, indicating a moderate surface drying effect of spring and summer temperatures (Figure 6c).

The total amount of summer NDVI variance explained by the combined influence of temperature and moisture controls in spring and summer varies strongly along the major climate gradients and vegetation types (Figure 6d). However, this generally reflects the influence of a single limiting factor rather than a combination of both, since areas with strong moisture and temperature limitation rarely overlap. Individually, moisture and temperature significantly influence summer NDVI in about $29 \%$ (mean $r^{2}=0.29 \pm 0.16$ ) and $43 \%$ (mean $r^{2}=0.25 \pm 0.12$ ) of the northern vegetated land, respectively. In the remaining $28 \%$ of the vegetated land neither temperature nor moisture appear to influence variations in photosynthetic activity significantly. This is true for parts of the boreal forests in central Eurasia, shrublands north of the treeline in the far east of Eurasia and northern Alaska, most of the European croplands and mixed forests in eastern North America. Beside potential issues related to the quality of the climate fields or NDVI data over very dense canopies, this might suggest that some large-scale, possibly non-climatic factors are driving interannual variations in peak summer vegetation photosynthetic activity in these regions.

Figure 7. Maps of additional variance $\left(R^{2}\right)$ explained by the univariate dynamic Kalman filter regression model between NDVI and potential climate drivers compared with a standard least squares linear regression model. $R^{2}$ gain for summer NDVI regressed onto: (a) spring and summer temperature; (b) spring and summer water supply; and (c) spring and summer soil moisture (scPDSI). A 10-year high-pass filter was applied to the data prior to analysis. $R^{2}$ values are shown for grid points where the dynamic regression model was selected over the standard fixed model based on the minimum Akaike Information Criteria (AIC). The rectangles show two regions for which time-dependent associations are illustrated in Figure 8.
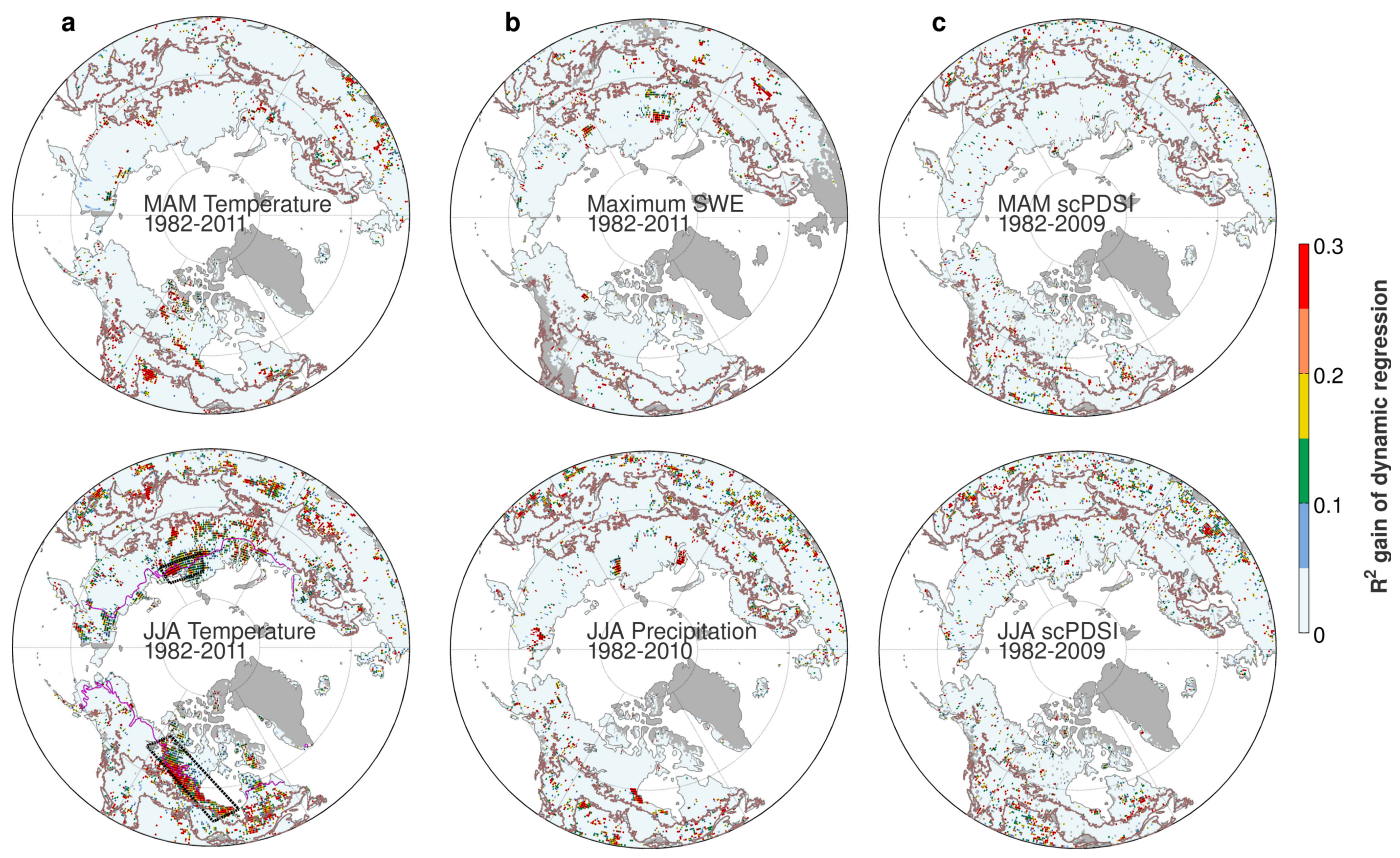


\subsubsection{Kalman Filter Regression}

Dynamic regression analysis with the Kalman filter shows little temporal dependence in the associations between interannual summer NDVI anomalies and spring and summer water supply, soil moisture and temperature variability across the study domain (Figure 7). There are no regions showing simultaneous time-dependent associations of NDVI with moisture and temperature that could indicate temporal shifts from temperature to moisture limitation. Time-dependent associations tend to occur in scattered grid boxes and in some small isolated regions, where local changes in NDVI linked to disturbances and land use change are more likely to produce temporal changes in the empirical associations. However, the analysis highlights some extensive temperature-limited regions in northern Canada and Siberia where the association between summer NDVI and summer temperature has changed substantially during the period 1982-2011 (Figure 7a). A visual comparison of NDVI and temperature series averaged over each of these regions shows that in the region located in northern Canada there was no significant association between summer NDVI and summer temperature during the 1980s, but thereafter the association became increasingly strong and significant, particularly since the late 1990s (Figure 8a). The opposite occurs in the Siberian region, where summer NDVI was significantly associated with summer temperatures during the 1980s and 1990s, but the association became insignificant during the 2000s (Figure 8b).

Figure 8. Illustration of the time-dependent association between interannual variability in summer NDVI and summer temperature in the regions indicated by the rectangles in Figure 7a. (a) Comparison of spatially averaged time series for the region in northern Canada (top) and the corresponding Kalman filter regression coefficients and pointwise confidence intervals over the period 1982-2011 (bottom). Where any of the confidence limits includes zero, the regression weights are not considered statistically significant at that point in time. The monthly number of station temperature records in the region included in the CRU TS 3.20 dataset is also shown (bottom). The Aqua-MODIS NDVI average for the same region is shown as a dotted line for comparison. The overall correlation between NDVI3g and temperature is displayed along with its significance $(*: p<0.05)$; (b) Same as (a) but for a region in Siberia.
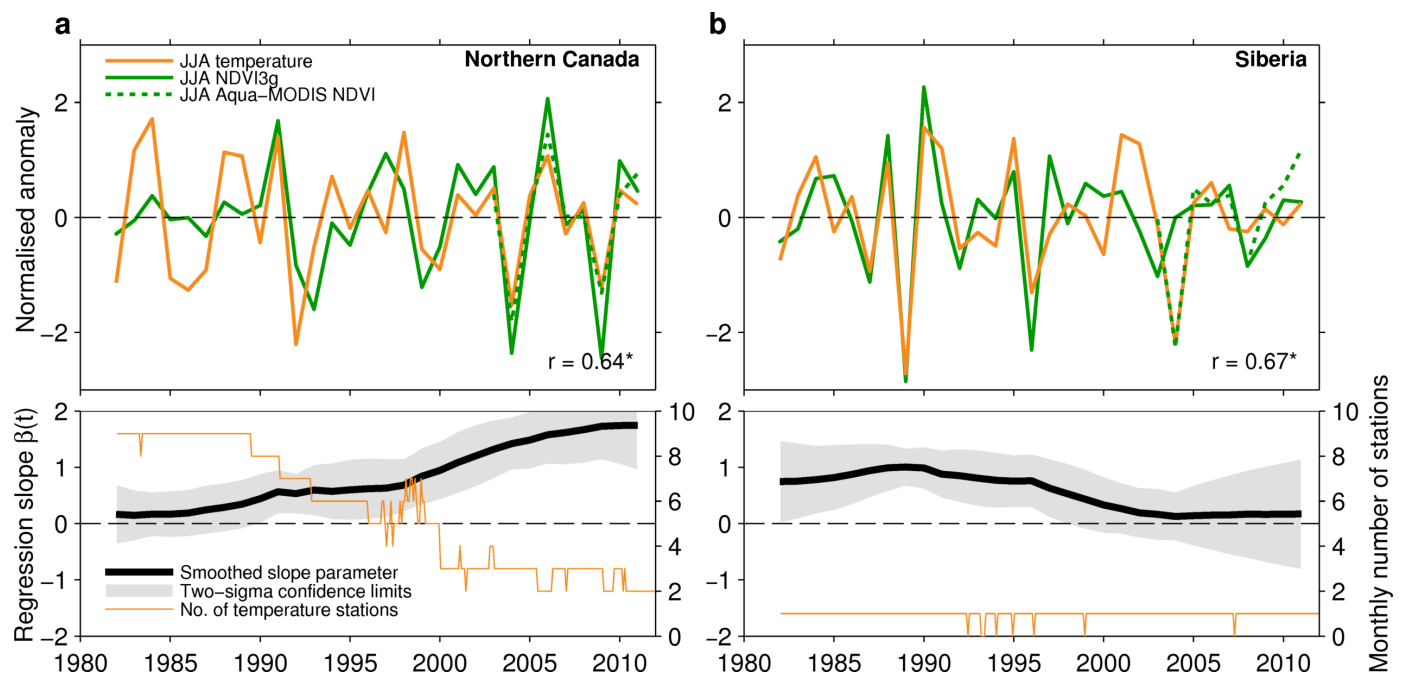
These regional-scale changes in empirical associations may be related to temporal changes in data quality in these remote regions rather than to real shifts in the temperature response of vegetation, but the exact causes are difficult to ascertain. The gridded temperature data comprise very few station records in these regions and might contain large uncertainties, particularly during the past decade (Figure 8a,b). Changes in satellite sensors and data processing could also potentially affect the variability in NDVI3g and its association with temperature. In Siberia, Aqua-MODIS NDVI agrees better than NDVI3g with temperature anomalies during the 2000s (Figure 8b), suggesting that the apparent loss of temperature response in NDVI3g data over this region likely reflects a change in data quality. Alternatively, this could simply indicate a lesser ability of the coarse NDVI3g data to resolve a spatially heterogeneous change in vegetation composition in the landscape compared with MODIS data.

\subsection{Trends in NDVI and Climate Constraints}

Significant spring and summer warming since the 1980s has alleviated cold constraints for temperature-limited vegetation, resulting in widespread summer greening trends over most of the circumpolar Arctic region and some parts of the Eurasian boreal forests in Scandinavia and eastern Siberia (Figure 9a,c). However, there are also strong greening trends in regions where climate has not warmed or interannual summer NDVI anomalies are not associated with temperature or moisture variability, suggesting a spatially consistent influence of some possibly non-climatic factors on summer vegetation trends. Again, this includes the extensive areas of the Eurasian boreal forests and shrublands in most of northern Alaska and parts of north-western Canada where interannual climate variability does not appear to control summer NDVI anomalies (Figure 6d). The region experiencing strong greening in northern Alaska appears to be closely associated with continuous permafrost conditions (Figure 9c; [61]). Thus, extensive changes in permafrost dynamics that favor shrub growth could be driving this regional greening.

Strong drying and warming over most of the moisture-limited Eurasian steppes has not been associated with significant changes in summer photosynthetic activity and only localized browning trends have occurred in the Mongolian steppes south of Lake Baikal (Figure 9c). Unlike the grasslands, most of the European and Canadian croplands have greened. This is generally consistent with coincident positive spring and summer moisture trends.

Most of the North American evergreen needleleaf boreal forests and adjacent open woodlands covering most of the discontinuous permafrost region up to the latitudinal treeline have experienced widespread browning trends whilst Arctic vegetation underlain by continuous permafrost has greened (Figure 9c). NDVI declines are widespread but spatially heterogeneous and occur in both temperature- and moisture-limited regions. Areas showing significant temperature or moisture trends are also scattered in space and are difficult to compare with NDVI trends, but most of the regions north of the boreal forest have warmed and drying trends are more common in the western half of the continent (Figure 9a,b). The only consistent moisture-related change across most of the northern part of the continent is a widespread decline in peak SWE (Figure 9b). Since interannual variability in winter snowpack is significantly associated with summer NDVI anomalies in large areas of the North American 
boreal forests (Figures 4b and 6a), declining snowpack is likely to be influencing the pattern of observed summer NDVI trends.

Figure 9. Linear trends in summer NDVI and dominant climate drivers since 1982. (a) Trends in spring and summer temperature between 1982 and 2011; (b) Trends in maximum SWE and summer scPDSI over the periods 1982-2011 and 1982-2009, respectively; (c) Statistically significant ( $p<0.1$ ) trends in summer NDVI between 1982 and 2011. The colored stippling indicates regions where spring-summer moisture (purple) and temperature (blue) variability significantly influence interannual summer NDVI anomalies as shown in Figure 6b,c. The black thick line in North America denotes the southern edge of the continuous permafrost region [61].
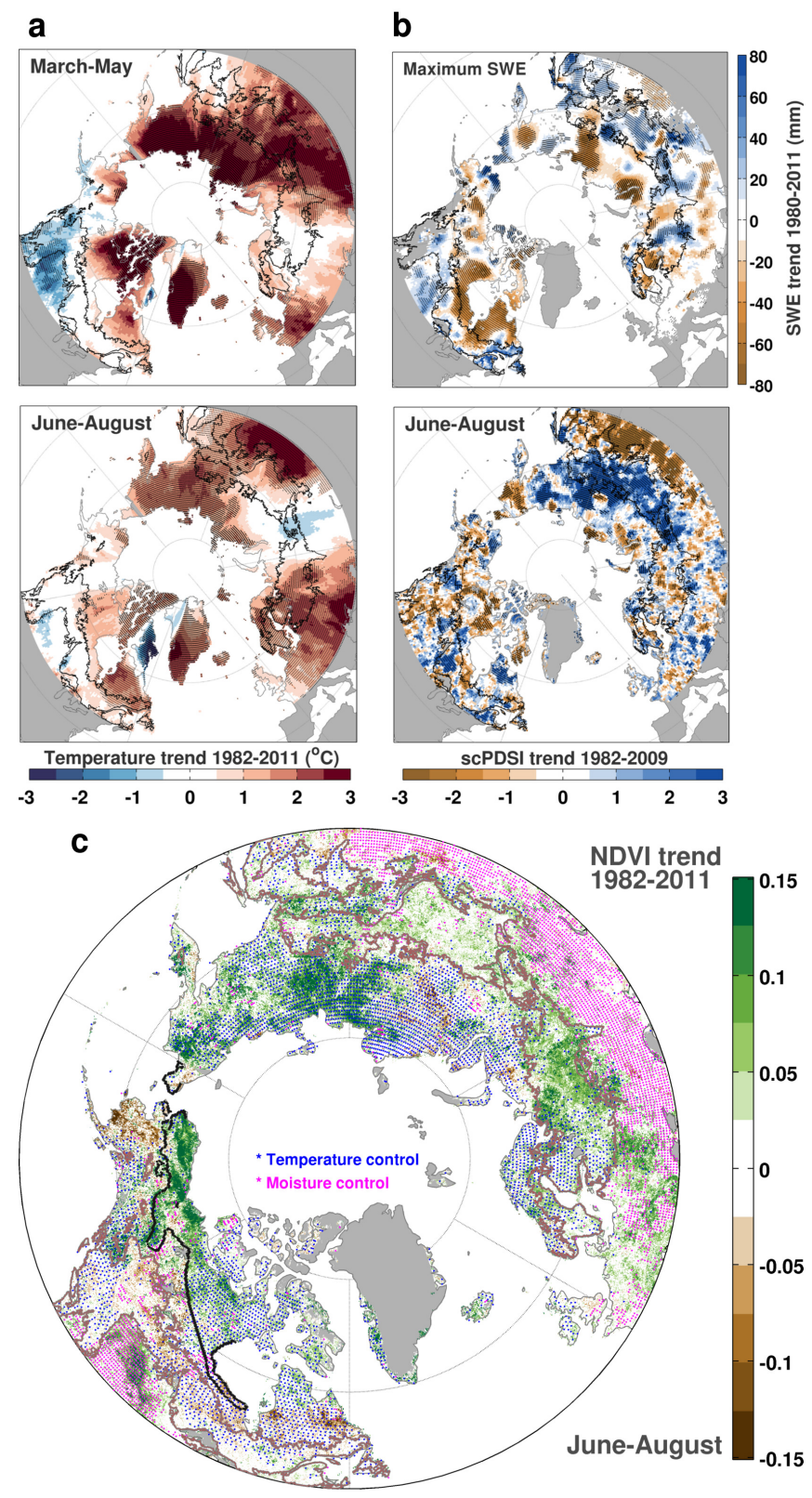
Figure 10. Temporal and spatial patterns of the leading Maximum Covariance Analysis (MCA) mode between maximum SWE and summer NDVI fields in boreal and Arctic regions of North America computed over the period 1982-2011. This mode explains $26.9 \%$ of the total cross-covariance and the correlation between the corresponding time expansion coefficients is 0.88 .

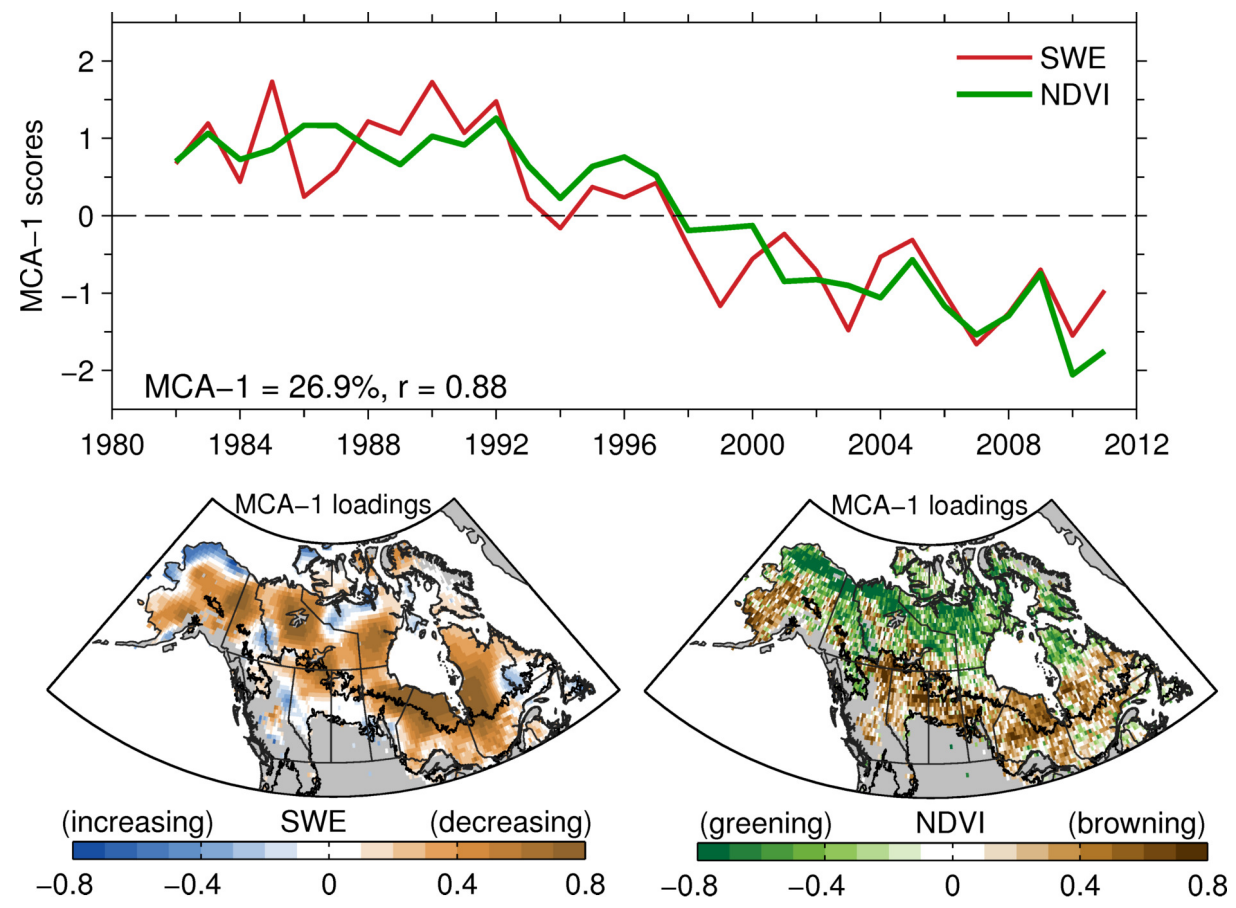

In order to quantitatively isolate any patterns of common temporal variability in winter snowpack and subsequent summer photosynthetic activity in North America, we applied a Maximum Covariance Analysis (MCA) to the NDVI and maximum SWE fields over the period 1982-2011. MCA identifies a coupled pattern of declining winter snowpack and summer NDVI since around 1991/1992 as the leading mode of common variability (Figure 10), explaining $27 \%$ of the total cross-covariance. The corresponding spatial loadings represent the spatial patterns of linear trends in maximum SWE and summer NDVI shown in Figure 9b,c, with contrasting browning trends in the boreal forests and greening trends in the Arctic shrublands and tundra in response to a common decline in snowpack accumulation.

A different pattern emerges when performing MCA using summer temperature and NDVI (Figure 11). In this case the leading mode of coupled variability accounts for $31 \%$ of the total cross-covariance and shows an overall increasing trend with large interannual anomalies, among which is the short-term cooling in 1992 associated with the eruption of Mount Pinatubo. The corresponding spatial loadings indicate that this pattern represents a contrast between eastern and western North America. Coupled warming and greening trends occur across the temperature-limited regions in north-eastern Canada, whereas cooling and browning are associated in the western side of the continent. The loadings also show that in the moisture-sensitive region along the western interior of Canada, warming trends coincide with weak or negative NDVI trends. Together with concurrent negative correlations at interannual scales (Figures $3 \mathrm{a}$ and $5 \mathrm{a}$ ), this suggests a weak sensitivity of summer NDVI to increased evapotranspiration demand with summer warming in this region. 
Figure 11. Temporal and spatial patterns of the leading MCA mode between summer temperature and summer NDVI fields in boreal and Arctic regions of North America computed over the period 1982-2011. This mode explains $31 \%$ of the total cross-covariance and the correlation between the corresponding time expansion coefficients is 0.82 .
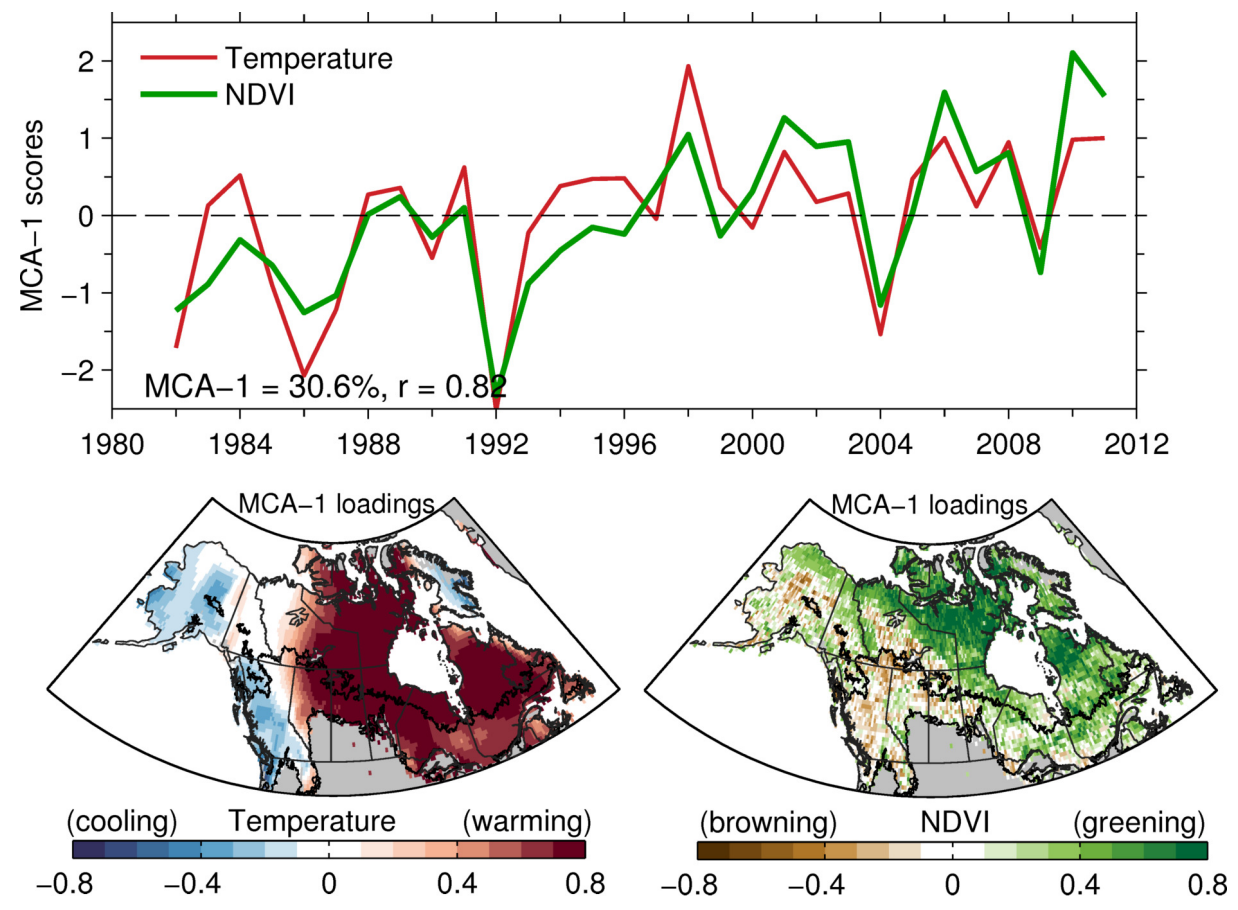

Figure 12. Temporal and spatial patterns of the leading MCA mode between March-August scPDSI and summer NDVI fields in boreal and Arctic regions of North America computed over the period 1982-2009. This mode explains $21 \%$ of the total cross-covariance and the correlation between the corresponding time expansion coefficients is 0.97 .
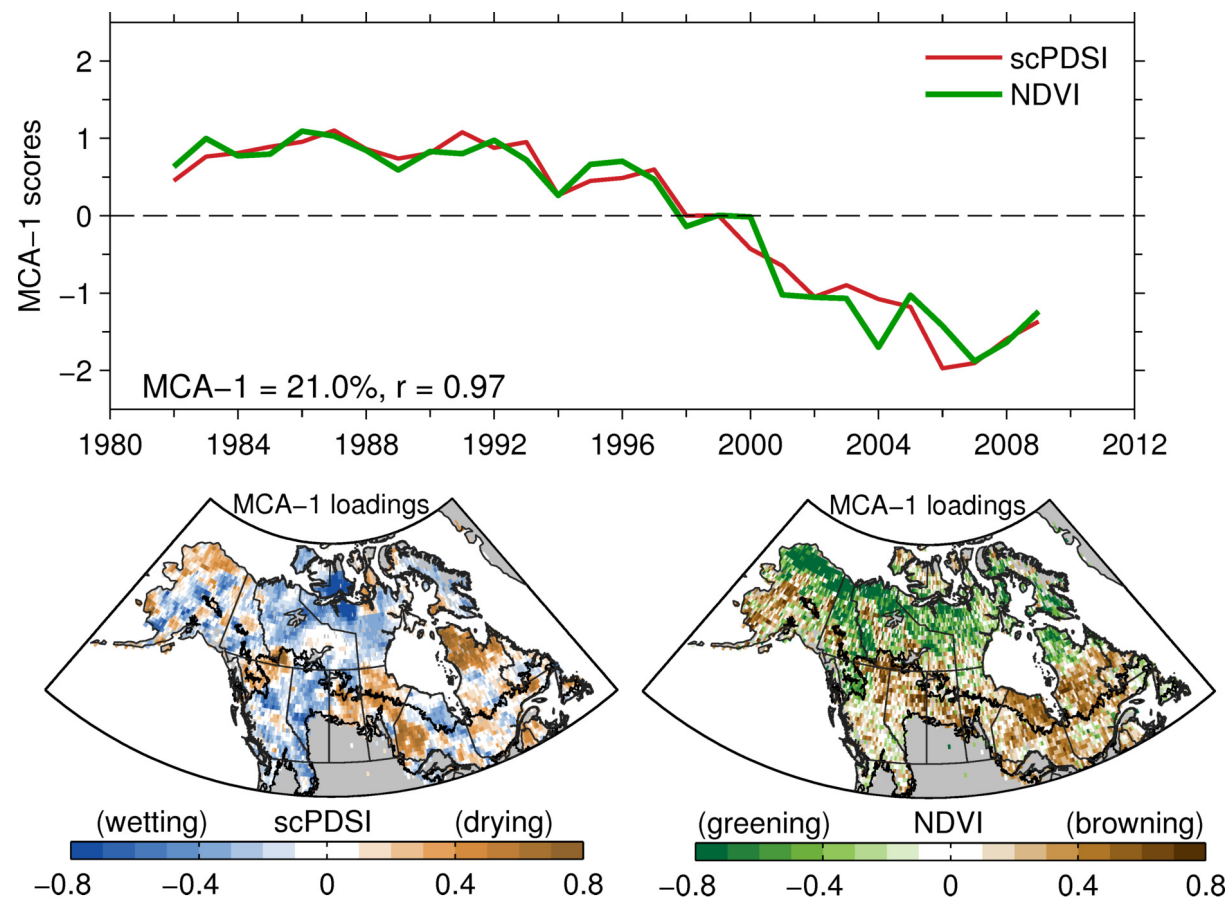
The MCA analysis was repeated using summer NDVI and spring-summer scPDSI over the period 1982-2009 in order to assess the NDVI response to the combined influence of changes in snow and evapotranspiration on soil water balance. The resulting coupled spatiotemporal pattern accounts for $21 \%$ of the total cross-covariance and is similar to that obtained with maximum SWE, but with a less coherent spatial pattern despite a slightly stronger temporal correlation (Figure 12). Taken together, these coupled spatiotemporal patterns consistently suggest that the observed trends in summer NDVI in North America can be largely explained by the combined effect of summer warming and a widespread decline in winter snowpack accumulation and summer moisture availability since around 1991.

The browning trends in the boreal forests and greening trends in the cool Arctic region indicate contrasting vegetation responses to these interrelated environmental changes. On the one hand, declining snowpack together with summer warming reduces summer soil moisture availability, which has an adverse impact on summer photosynthetic activity in the dense and open (woodland) boreal forests. The similarity of the patterns shown in Figures 10 and 12 indicates that the decrease in summer moisture availability in the boreal region is primarily driven by reduced snow water supply whilst increased evapotranspiration demand with summer warming has a secondary effect that contributes to further drying. On the other hand, the same combination of reduced snow accumulation and warmer summers stimulates the greening of Arctic vegetation, likely due to the lengthening of the short growing seasons and changes in permafrost and possibly nutrient availability.

\section{Discussion}

\subsection{Sensitivity of High-Latitude Drought to Surface Warming}

Arctic and boreal terrestrial ecosystems are experiencing rapid climatic change, with surface temperatures rising by about $2-3{ }^{\circ} \mathrm{C}$ since 1950 and a notable increase in cold season precipitation and widespread snow cover reduction [62]. Using an improved scPDSI dataset, we have estimated the relative contribution of changes in moisture supply (rainfall and snow) and atmospheric evaporative demand (potential evapotranspiration) on summer soil moisture variability at northern latitudes between 1950 and 2009. We found that increased evapotranspiration demand, driven mainly by surface warming, has significantly influenced summer drought severity in the northern latitudes since the late 1980s. The estimated enhancement of atmospheric moisture demand during this recent period has been balanced by the increase in precipitation in the northern latitudes and thus has not yet imposed an increasing trend in drought area (Figure 1a).

This finding is consistent with the ongoing intensification of the hydrological cycle observed at high latitudes due to increases in both precipitation and evapotranspiration [63,64]. A similar impact of surface warming on drought severity since the 1980s has been documented on a global scale by recent studies based on the scPDSI using a Penman-Monteith formulation for potential evapotranspiration, but forced with different meteorological datasets $[11,43,65,66]$. As in these earlier scPDSI-based studies, the use of the more physically realistic Penman-Monteith, rather than the Thornthwaite, parametrization for potential evapotranspiration improves the applicability of the index under global warming scenarios but it needs additional meteorological forcings (such as radiation, wind, humidity 
and vapor pressure) for which estimates are less reliable and have less spatial coverage than temperature. The magnitude of the influence of these uncertain forcings on soil moisture changes is likely to be underestimated in our results. However, a similar pattern of temperature-driven amplification of drought at northern latitudes was observed in an earlier study using an offline simulation of the terrestrial hydrological cycle using a land-surface model driven by a hybrid reanalysis-observation forcing dataset between 1950 and 2000 [67].

The impact of increased evapotranspiration demand on the summer moisture balance has been stronger and more widespread in Eurasia than in North America, but the timing and magnitude were found to vary considerably within each continent following the spatiotemporal patterns of summer warming (Figure 2). Boreal and northern temperate North America are the only regions in our study domain where there has been no significant summer warming since the late 1980s and thus atmospheric moisture demand has not increased in recent decades. These spatiotemporal patterns imply that the severe regional droughts observed in boreal and temperate North America during recent years (e.g., 1988, 2001-2003; [4,68,69]) have been driven exclusively by precipitation deficits. In contrast, since the 1990s, warming-driven evapotranspiration demand has been an additional factor driving the severity and extent of regional droughts documented in northern North America (e.g., 1998, 2004; [70,71]) and most of northern and inner Eurasia (e.g., 2001, 2010; [4,72,73]).

Regional soil moisture variability during the spring snowmelt period, when soils are close to field capacity, has also been influenced by warming and the associated increases in evapotranspiration demand (Figure A3), but only marginally when compared with hotter summer months when soils are drier and evapotranspiration rates are near their seasonal peak (Figure 2). Therefore, in contrast to summer, moisture demand in spring has not counteracted the increasing circumpolar trend in soil wetness induced by increasing precipitation. This pattern of cold season wetting and summer drying with recent warming is consistent with some model projections of seasonal changes in soil moisture at high latitudes in response to anthropogenic warming [74], which were first made about 30 years ago [75].

Ongoing trends toward thinner snowpacks and earlier snowmelt and growing seasons $[9,36,38]$ may be further enhancing summer drying in some regions by extending the period of evapotranspiration into the spring and thus accelerating seasonal soil moisture depletion [10,35]. Indeed, pioneering modeling studies conducted in the 1980s using simple climate models suggested that, along with increasing evaporation demand, earlier snowmelt also contributed to projected summer drying at northern latitudes as a result of anthropogenic warming [75]. The snow model implemented in our formulation of the scPDSI may capture the influence of changes in snow accumulation on soil moisture dynamics (Figure A6c) more accurately than changes in the timing of the snowmelt. This is because the (monthly) resolution of the meteorological forcing data is quite coarse. However, the timing of snowmelt is closely associated with the amount of snow accumulated in the winter snowpack [33] and thus our scPDSI estimates may still incorporate the effect of the widespread reduction in spring snow cover observed at northern latitudes [36].

In permafrost soils, the simple scPDSI model provides only a limited indication of potential changes in regional soil water balance. Permafrost dynamics exert a strong control on the local water balance of the seasonally active soil layer. The active layer stores water surplus from late summer and autumn rainfalls during freezing and then gradually releases it over the course of the following warm season as 
the thawing depth increases [76]. This interannual moisture transfer combined with water supply from the deeper thawing layer can sustain summer evapotranspiration and vegetation growth during periods of meteorological drought [76,77]. In some cases, late summer droughts can be carried to the next spring if snowmelt does not replenish soil moisture [78]. Permafrost water seems to be less important during rainy summers, when evapotranspiration is maintained mainly by rain water [77]. Long-term changes in permafrost and active layer depth with ongoing warming can decrease or increase soil moisture availability depending on complex interactions between topography, permafrost characteristics, vegetation and snow cover $[79,80]$. None of these these seasonal and long-term changes in permafrost dynamics are included in the water balance of the scPDSI and thus our moisture estimates in permafrost soils of the Arctic region might differ substantially from actual moisture anomalies.

The inferred enhancement of atmospheric moisture demand and shifts to earlier spring snowmelt observed during recent decades might have impacted ecosystem processes in the northern latitudes. Changes such as the widespread disappearance of shallow Arctic ponds [81] and the intensification of fire regimes in the boreal zone [78,82] are consistent with greater evaporative demand. How these changes in snow and evaporative demand may have impacted northern vegetation is discussed below in connection with regional greening and browning trends.

\subsection{Spatially Heterogeneous Controls of Interannual Variability in Summer Photosynthetic Activity}

Our results show that spring and summer moisture availability exerts significant control on the interannual variability of summer photosynthetic activity over about $29 \%$ (mean $r^{2}=0.29 \pm 0.16$ ) of the northern vegetated land, whilst temperatures during the same seasonal period exert a significant control over another $43 \%$ (mean $r^{2}=0.25 \pm 0.12$; Figures 3-6). However, the timing, magnitude and relative importance of these climate controls varies substantially between and within biomes, consistent with differences in climate responses between plant functional types observed in earlier studies [15,31]. Simple correlations suggest that summer temperature is the dominant control of summer anomalies of photosynthetic activity in the cool boreal and Arctic regions, whereas spring and summer soil moisture availability is the main control of summer photosynthetic activity across the continental interiors in the northern temperate grasslands and to a lesser extent in croplands (Figure 5). This interpretation is consistent with known patterns of climate constraints on vegetation productivity in northern biomes [3].

A new result of this study is that changes in cool-season snow accumulation exert a significant indirect influence on the variability of summer photosynthetic activity in cool regions where it is often assumed that summer vegetation growth is dominantly temperature-limited, such as most of the boreal forests and Arctic shrublands along the dry western interior of Canada and Alaska, and open forests and shrublands in dry subarctic regions in eastern and south-central Siberia (Figure 5). Interannual anomalies in summer photosynthetic activity in these areas are significantly and positively correlated with peak SWE, but correlations with summer rainfall and summer surface soil moisture anomalies based on the scPDSI and MW-SMO are weak (Figure 3). Positive correlations of summer photosynthetic activity with the scPDSI become stronger and more consistent with vegetation responses to peak SWE anomalies when including the spring melting period in the seasonal average (Figure 4). This suggests that summer vegetation photosynthetic activity in these relatively dry regions is sensitive to spring soil moisture recharge by 
snowmelt water at deeper layers of the rooting zone, a process that does not appear to be well captured by summer scPDSI and satellite retrievals.

At least a third of the yearly precipitation in these regions is stored in the winter snowpack (Figure A1e). The melting of the snowpack in spring typically produces a large seasonal pulse in soil moisture recharge that can sustain vigorous vegetation growth and evapotranspiration well into the growing season until the start of a second period of moisture recharge by summer rainfalls [83,84]. However, summer rainfall may replenish moisture near the surface but may be less effective in recharging deeper soil layers because a large fraction is lost to evaporation. As a result, for a given level of summer moisture demand, reductions in winter snowpack accumulation may induce greater drought stress than reductions in summer precipitation. This hypothesis is consistent with summer rainfall exclusion experiments in interior Alaska showing that tree growth in well-drained upland forests is maintained primarily by snowmelt water and is not affected by summer rainfall deficits [84].

Positive influences of deeper winter snowpack on subsequent peak summer photosynthetic activity and carbon uptake have been well documented in alpine forests in the western United States, where typically more than half of the annual precipitation falls as snow [32,33]. These mountain forests rely heavily on snowmelt water even late into the growing season and variations in maximum snow accumulation can explain over $50 \%$ of the interannual variability in peak forest photosynthetic activity [33]. Earlier growing seasons in these snow-dominated environments correlate with shallower snowpacks and result in reduced rather than increased growing season productivity because of insufficient spring soil moisture recharge to sustain summer growth [32]. In the northern latitudes, a positive association between summer NDVI and deeper snowpack has been previously documented in the taiga (subarctic woodland) and steppes of central Siberia [34], consistent with our results for these regions (Figure 4b). This association has been interpreted as a positive vegetation response to increased water availability after snowmelt and also to enhanced thermal insulation of soils by thicker snowpacks during the cold Siberian winters.

Similar to the alpine forests in the western United States, a negative influence of earlier spring ground thaw on peak forest photosynthetic activity has been recently documented across the drier western and central sections of the North American boreal forests [35]. Our results show that maximum snow accumulation in these regions explains on average about $20 \%$ of the interannual variance of summer NDVI (Figures $4 \mathrm{~b}$ and $6 \mathrm{a}$ ). Thus, this negative response of summer photosynthetic activity to earlier spring thaw is likely a reflection of soil moisture deficits resulting from both insufficient soil moisture recharge with shallow snowpacks and increased moisture depletion with an extended evaporative season. Taken together, these emerging results suggest that recent changes in snow regimes associated with rapid climatic warming [36-38] are likely to have played an important, albeit unrecognized, role in the observed spatiotemporal patterns of summer photosynthetic activity across a large portion of the boreal region, particularly in North America.

Earlier studies have reported an apparent shift towards increased moisture limitation of vegetation productivity with continued warming since the the early 1990s across much of the temperate and boreal ecosystems $[4,15,21]$. Our results indicate that the interannual association between climate (temperature, moisture and snow) and NDVI variability has not changed over time (Figure 7) and thus there is no evidence for consistent regional-scale temporal shifts from temperature to moisture limitation with 
recent warming on a year-to-year basis and at the grid box level. Time-dependent associations between temperature and NDVI were found only in some remote northern regions where data quality is probably low (Figure 8). The temporal stability of the climate responses of summer NDVI at interannual time scales indicates that the apparent changes in climate response found in previous studies are linked to decadal time scales, where NDVI variability can be affected by a variety of other slowly-varying climatic and non-climatic factors $[85,86]$. Also, previous studies have typically used continental or circumpolar averages for assessing the responses of NDVI. Large-scale averages are likely to include biomes or regions with contrasting climatic controls or little climate control (Figure 5) and thus may give an ambiguous picture of vegetation responses to climate.

Our results highlight extensive regions where there is no significant linear association between interannual variations in summer NDVI and spring or summer climate variability, such as the boreal forests in central Eurasia, shrublands in the far east of Siberia and northern Alaska, European croplands and mixed forests in eastern North America (Figures 6d). Collectively, these regions represent $28 \%$ of the northern vegetated land. Land management practices (e.g., grazing, irrigation, harvest, etc.) can easily override climate influences on NDVI in the croplands and some intensively managed grasslands, but it is less clear which factors are driving interannual NDVI anomalies in undisturbed forests and remote high-latitude shrublands.

Correlations at short lags (1-2 years) did not show significant lagged climate responses in these regions (results not shown here). Uncertainties in the climate datasets and in NDVI might account in part for the apparent lack of climate response. Extremely sparse coverage in the meteorological station network underlying the gridded temperature and particularly the precipitation fields could be reducing the correlations in the remote Arctic shrublands. The few data available might not represent coastal or mountainous areas well, where local climate conditions driving NDVI variability may differ substantially from conditions averaged over more continental regions. Moreover, permafrost and snow dynamics could also be modulating interannual climate-soil-vegetation interactions in these cold and dry regions.

\subsection{Drivers of Vegetation Greening and Browning Trends}

Warming has stimulated productivity rates of northern vegetation by lifting low temperature limitations on vegetation metabolism [3,4]. We find that practically all temperature-limited Arctic and boreal regions have greened since 1982, consistent with concurrent warming trends (Figure 9a,c). Moreover, a slight regional cooling in western Canada is consistent with co-located browning trends, as documented in earlier regional studies [87]. This is an indication that temperature-limited vegetation across the circumpolar region (43\% of the northern vegetated land) has responded to temperature variability in a consistent manner at interannual and longer time scales, with no apparent decoupling between warming and greening trends during summer.

Another interesting result of our grid box-scale comparisons is that warming is not the only driver of the widespread greening in the cool northern biomes. Most regions where NDVI is not correlated with climate on a year-to-year basis ( $\sim 28 \%$ of the northern vegetated land) have also greened (Figure 9c). This suggests the influence of other climatic or non-climatic factors not accounted for in this study, operating at longer time scales and across different vegetation types. A number of possible factors 
could be at work but quantifying their relative contribution to these greening trends would require further analysis and is beyond the scope of this study. In part, these greening trends could indicate the effect of $\mathrm{CO}_{2}$ fertilization on northern vegetation, as seen in modeling studies [85], but such a strong effect is unlikely in cool boreal regions [88]. Changes in permafrost seem to be a factor stimulating greening trends in some subarctic regions. For instance, extensive shrublands underlain by continuous permafrost in northern Alaska show a consistent greening trend despite a lack of interannual correlations with climate (Figure 9c). Shrub encroachment has been identified as an important driver of this regional greening [89] and it is likely that this reflects gradual, warming-driven changes in permafrost dynamics and snow cover that favor shrub establishment. Significant declines in sea ice along the Arctic coast might have also contributed to the widespread greening of coastal tundra vegetation underlain by permafrost [90].

The combined influence of warming and the positive effect of other undetermined factors has led to stronger and more widespread greening trends in Eurasia than in North America. Most of the Eurasian boreal forests and Arctic regions have greened, whereas in North America only the Arctic region underlain by continuous permafrost north of the treeline has greened and most of the boreal forests have undergone browning trends. Although these contrasting continental and biome trends have been documented in earlier analyses of the GIMMS NDVI record [9,15-17,19,22], our empirical results highlight the significant role of factors other than temperature and moisture on these vegetation patterns. A similar regional heterogeneity in the drivers of the greening trends in northern ecosystems has been found in attribution studies based on ecosystem models [85]. Further regional studies are needed to understand the influence of changing permafrost and other non-climatic factors on the ongoing greening of northern landscapes and to explore the potential for future changes and their controls.

Forest browning across most of Canada and Alaska since the early 1990s has led to speculation that after an initial alleviation of cold constraints during the 1980s, subsequent warming has no longer promoted northern vegetation growth because of increased temperature-induced drought stress $[15,16,18,21]$. This hypothesis has emphasized the role of increasing evaporative demand on surface water budget, whilst the potential influence of changes in moisture supply (snow and rainfall) and connections with concurrent changes in snow regimes have not been considered. The results from our Maximum Covariance Analysis suggest that NDVI declines across the North American boreal forests since around 1991/2 are linked with a long-term decrease in summer soil moisture availability, as measured by spring-summer scPDSI (Figure 12). However, a new finding of this study is that the decrease in moisture availability seems to have occurred primarily in response to declining snowpack water content and subsequent reductions in moisture recharge from spring snowmelt. The effect of increasing evaporative demand associated with summer warming appears to be a secondary factor contributing to further drying and browning in some locations (Figure 11). Thus, our results do not fully support the hypothesis of temperature-induced drought stress, which overemphasizes the role of temperature on the soil water budget and overlooks the influence of snow in the boreal region.

Using Maximum Covariance Analysis to isolate the coupled trends in winter snowpack (maximum SWE), soil moisture availability (scPDSI) and summer NDVI in North America has shown that the temporal pattern of shared trends is strongly consistent with the temporal trajectory of regional-scale declines in NDVI, tree-ring growth, forest biomass and modeled productivity previously documented 
in the boreal region (e.g., [15,18,35,70,91]). Furthermore, the spatial patterns of the coupled trends suggest contrasting vegetation responses to declining snowpack accumulation in the Arctic shrublands and boreal forests since the early 1990s. Thus, together with seasonal warming, declining snow cover appears to be playing an important role in driving the well-documented contrast between forest browning and tundra greening trends in North America $[15,16,18]$. Reduced peak snow accumulation can extend the short northern growing seasons and stimulate earlier and faster vegetation greening in some cool Arctic regions [34,90], but it may have an adverse impact in the boreal forests due to reduced water availability during summer [84] and soil insulation during the cold season [92,93].

Recent studies based on satellite and in-situ observations have shown that rapid winter/spring warming and changes in interdecadal climate modes since around 1991 have led to a significant decline in snowpack accumulation and snow cover duration across most of Alaska and Canada despite increasing winter precipitation [36-38,94,95]. In some regions of the North American Cordillera, the recent loss of snowpack is unprecedented over the past millennium [96]. Estimates based on satellite retrievals for the period 1979-2007 indicate a reduction in December-April SWE of about 0.4 to $0.5 \mathrm{~mm} \mathrm{yr}^{-1}$ over North America, which corresponds to an overall reduction of snow depth of about 5-8 cm in 29 years, depending on snow density [38]. Without increases in summer precipitation, this reduction in snowpack is sufficient to result in soil moisture deficits later in the growing season over extensive boreal regions relying on spring snowmelt for water supply (Figure 4). Summer warming and the associated increase in evaporative demand could exacerbate surface drying and vegetation stress. However, weak negative correlations between summer temperature and NDVI anomalies over moisture-sensitive areas, such as in the continental interior of Canada and Alaska (Figure 5a), suggest that this extra drying effect has been small.

The significant sensitivity of the North American boreal forests to changes in snow hydrology has not been fully appreciated until now and could help explaining the apparent changes in climate sensitivity of tree growth in the region [26]. It also raises concerns regarding forest responses to continued warming and possible impacts on the carbon cycle. The result of the lagged coupling between vegetation and seasonal snow dynamics is consistent with the hypothesis that spring productivity gains from earlier thaw and extension of the growing season could potentially be offset by drought-induced productivity losses later in the season [4,16,21,35]. Since most Dynamic Global Vegetation Models (DGVMs) have only a limited ability to realistically simulate snowpack dynamics and feedbacks in forested regions [97,98], the sensitivity of the boreal forests to snow hydrology described in this empirical study may not be well captured in current simulations of the carbon cycle.

Climate models participating in the Coupled Model Intercomparison Project Phase 5 (CMIP5) project a shift towards low spring snow accumulation in the Northern Hemisphere despite a concurrent increase in winter precipitation, with parts of the North American boreal zone showing the strongest snow reductions during the near term decades when global mean surface temperatures rise to $2{ }^{\circ} \mathrm{C}$ above the pre-industrial baseline [99]. Combined with projections of parallel increases in evapotranspiration demand [11], this will likely result in further lengthening and intensification of the period of summer drought stress and thus induce productivity losses across moisture-sensitive regions with snow-dominated hydrology. 


\section{Summary and Conclusions}

We have shown that increased evapotranspiration demand accompanying rapid summer warming since the late $1980 \mathrm{~s}\left(\sim 0.7{ }^{\circ} \mathrm{C}\right)$ has become a significant driver of summer drought severity in the northern latitudes, offsetting the effect of increasing cold-season precipitation. This result is consistent with ongoing amplification of the hydrological cycle and with model projections of summer drying at mid and high latitudes in response to anthropogenic warming. The climatic control of summer NDVI across northern biomes is significant but highly heterogeneous in space. Unlike previous studies, our results show a strong regional influence of snow dynamics and possibly non-climatic factors on the interannual variability and trends in summer NDVI over vast areas of the boreal and Arctic regions, where temperature is often assumed to be the dominant environmental control of vegetation productivity. Predominantly temperature-limited and moisture-limited vegetation growth has responded consistently to climate variability at interannual and longer time scales, with no apparent decoupling between climate and NDVI trends. Thus, in contrast to earlier regional-scale studies our results do not show evidence for temporal shifts in the type or magnitude of climate limitation at the grid box scale.

Widespread NDVI declines across the North American boreal forests since around 1991/2 are consistent with a long-term increase in summer drought stress. However, the increase in drought stress may have occurred primarily in response to declining snowpack accumulation and insufficient soil moisture recharge from spring snowmelt rather than to temperature-induced increases in evaporative demand as hypothesized in earlier studies. Although summer warming has contributed to surface drying and NDVI declines through increased evaporative demand, the relative role of temperature on the soil water budget may have been overemphasized in previous remote sensing studies.

These results have important implications for the functioning of northern ecosystems under future climate projections. Further increase in evapotranspiration demand and reduction in snowpack accumulation with any continued warming during the coming decades could intensify summer drought severity and disturbance regimes despite projected increases in cold season precipitation. However, highly heterogeneous vegetation responses to these changes should be expected across the circumpolar region. The skill of current process-based ecosystem models to simulate these empirically inferred, snow-mediated moisture controls on regional photosynthetic activity requires investigation. This is necessary if the impacts of projected snowpack changes on net ecosystem carbon balance are to be estimated. Furthermore, regional studies should evaluate vegetation responses to environmental factors not considered in this study (e.g., $\mathrm{CO}_{2}$ and nitrogen fertilization, disturbance and permafrost dynamics), which could explain changes in summer photosynthetic activity in the vast regions where NDVI anomalies were not associated with temperature and moisture variability. Separating the relative roles of these factors on vegetation growth patterns during the satellite period is necessary for accurately predicting potential responses of northern vegetation to novel climate regimes.

\section{Acknowledgments}

We thank Ryan Teuling and Frank Janssen for sharing their Matlab code for bivariate color maps and multivariate statistics (MVSTAT toolbox), respectively. We also thank Ed Cook for sharing his Fortran 
routine for Kalman Filter Regression. Liang Xu and Jiang Bi (Boston University) kindly provided the land cover and continuous vegetation fields data at the spatial resolution of GIMMS NDVI3g. JB was supported by a doctoral scholarship from the Chilean Government under the program Formación de Capital Humano Avanzado of CONICYT and recently by a grant from the School of Environmental Sciences of the University of East Anglia. KRB, TJO and TMM acknowledge support from UK NERC (under grant NE/G018863/1). RBM acknowledges support from the NASA Earth Science Division. The contribution of WD was supported by ESA's Climate Change Initiative for Soil Moisture (Contract No. 4000104814/11/I-NB). We thank Jorge Pinzon for technical discussions and three anonymous reviewers for their helpful comments.

\section{Author Contributions}

Jonathan Barichivich and Keith R. Briffa designed research with contribution of Timothy J. Osborn and Thomas M. Melvin; Ranga Myneni, Gerard van der Schrier, Wouter Dorigo and Compton J. Tucker provided vegetation and moisture data; Jonathan Barichivich performed the analyses and wrote the paper with contributions from all the authors.

\section{Conflicts of Interest}

The authors declare no conflict of interest.

\section{References}

1. Jarvis, P.; Linder, S. Constraints to growth of boreal forests. Nature 2000, 405, 904-905.

2. Roy, J.; Saugier, B.; Mooney, H. Terrestrial Global Productivity; Academic Press: Waltham, MA, USA, 2001.

3. Nemani, R.; Keeling, C.; Hashimoto, H.; Jolly, W.; Piper, S.; Tucker, C.; Myneni, R.; Running, S. Climate-driven increases in global terrestrial net primary production from 1982 to 1999. Science 2003, 300, 1560-1563.

4. Zhang, K.; Kimball, J.; Hogg, E.; Zhao, M.; Oechel, W.; Cassano, J.; Running, S. Satellite-based model detection of recent climate-driven changes in northern high-latitude vegetation productivity. J. Geophys. Res 2008, doi:10.1029/2007JG000621.

5. Myneni, R.; Keeling, C.; Tucker, C.; Asrar, G.; Nemani, R. Increased plant growth in the northern high latitudes from 1981 to 1991. Nature 1997, 386, 698-702.

6. Keeling, C.; Chin, J.; Whorf, T. Increased activity of northern vegetation inferred from atmospheric $\mathrm{CO}_{2}$ measurements. Nature 1996, 382, 146-149.

7. Piao, S.; Friedlingstein, P.; Ciais, P.; Viovy, N.; Demarty, J. Growing season extension and its effects on terrestrial carbon flux over the last two decades. Glob. Biogeochem. Cycle. 2007, doi:10.1029/2006GB002888.

8. Barichivich, J.; Briffa, K.R.; Osborn, T.J.; Melvin, T.M.; Caesar, J. Thermal growing season and timing of biospheric carbon uptake across the Northern Hemisphere. Glob. Biogeochem. Cycle. 2012, doi:10.1029/2012GB004312. 
9. Barichivich, J.; Briffa, K.R.; Myneni, R.; Osborn, T.J.; Melvin, T.M.; Ciais, P.; Piao, S.L.; Tucker, C. Large-scale variations in the vegetation growing season and annual cycle of atmospheric $\mathrm{CO}_{2}$ at high northern latitudes from 1950 to 2011. Glob. Chang. Biol. 2013, 19, 3167-3183.

10. Zhang, K.; Kimball, J.; Kim, Y.; McDonald, K. Changing freeze-thaw seasons in northern high latitudes and associated influences on evapotranspiration. Hydrol. Process. 2011, 25, 4142-4151.

11. Dai, A. Increasing drought under global warming in observations and models. Nat. Clim. Chang. 2012, 3, 52-58.

12. Turetsky, M.R.; Kane, E.S.; Harden, J.W.; Ottmar, R.D.; Manies, K.L.; Hoy, E.; Kasischke, E.S. Recent acceleration of biomass burning and carbon losses in Alaskan forests and peatlands. Nat. Geosci. 2010, 4, 27-31.

13. Peng, C.; Ma, Z.; Lei, X.; Zhu, Q.; Chen, H.; Wang, W.; Liu, S.; Li, W.; Fang, X.; Zhou, X. A drought-induced pervasive increase in tree mortality across Canada's boreal forests. Nat. Clim. Chang. 2011, 1, 467-471.

14. Tucker, C.; Pinzón, J.; Brown, M.; Slayback, D.; Pak, E.; Mahoney, R.; Vermote, E.; El Saleous, N. An extended AVHRR 8-km NDVI dataset compatible with MODIS and SPOT vegetation NDVI data. Int. J. Remote Sens. 2005, 26, 4485-4498.

15. Goetz, S.; Bunn, A.; Fiske, G.; Houghton, R. Satellite-observed photosynthetic trends across boreal North America associated with climate and fire disturbance. Proc. Natl. Acad. Sci. USA 2005, 102, 13521-13525.

16. Bunn, A.; Goetz, S. Trends in satellite-observed circumpolar photosynthetic activity from 1982 to 2003: The influence of seasonality, cover type, and vegetation density. Earth Interact. 2006, 10, 1-19.

17. Piao, S.; Wang, X.; Ciais, P.; Zhu, B.; Wang, T.; Liu, J. Changes in satellite-derived vegetation growth trend in temperate and boreal Eurasia from 1982 to 2006. Glob. Chang. Biol. 2011, 17, 3228-3239.

18. Beck, P.S.; Juday, G.P.; Alix, C.; Barber, V.A.; Winslow, S.E.; Sousa, E.E.; Heiser, P.; Herriges, J.D.; Goetz, S.J. Changes in forest productivity across Alaska consistent with biome shift. Ecol. Lett. 2011, 14, 373-379.

19. Xu, L.; Myneni, R.B.; Chapin, F.S., III; Callaghan, T.V.; Pinzon, J.E.; Tucker, C.J.; Zhu, Z.; Bi, J.; Ciais, P.; Tømmervik, H.; et al. Temperature and vegetation seasonality diminishment over northern lands. Nat. Clim. Chang. 2013, 3, 581-586.

20. Zhou, L.; Tucker, C.; Kaufmann, R.; Shabanov, N.; Myneni, R. Variations in northern vegetation activity inferred from satellite data of vegetation index during 1981 to 1999 . J. Geophys. Res. 2001, 106, 20-069.

21. Angert, A.; Biraud, S.; Bonfils, C.; Henning, C.; Buermann, W.; Pinzon, J.; Tucker, C.; Fung, I. Drier summers cancel out the $\mathrm{CO}_{2}$ uptake enhancement induced by warmer springs. Proc. Natl. Acad. Sci. USA 2005, 102, 10823-10827.

22. Beck, P.; Goetz, S. Satellite observations of high northern latitude vegetation productivity changes between 1982 and 2008: Ecological variability and regional differences. Environ. Res. Lett. 2011, doi:10.1088/1748-3182/6/4/049501. 
23. Barber, V.A.; Juday, G.P.; Finney, B.P. Reduced growth of Alaskan white spruce in the Twentieth Century from temperature-induced drought stress. Nature 2000, 405, 668-673.

24. Jacoby, G.C.; D'Arrigo, R.D. Tree ring width and density evidence of climatic and potential forest change in Alaska. Glob. Biogeochem. Cycle. 1995, 9, 227-234.

25. Briffa, K.R.; Schweingruber, F.; Jones, P.; Osborn, T.; Shiyatov, S.; Vaganov, E. Reduced sensitivity of recent tree-growth to temperature at high northern latitudes. Nature 1998, 391, 678-682.

26. D'Arrigo, R.; Wilson, R.; Liepert, B.; Cherubini, P. On the divergence problem in northern forests: A review of the tree-ring evidence and possible causes. Glob. Planet. Chang. 2008, 60, 289-305.

27. Wilmking, M.; Juday, G.P. Longitudinal variation of radial growth at Alaska's northern treeline-Recent changes and possible scenarios for the 21st century. Glob. Planet. Chang. 2005, 47, 282-300.

28. Juday, G.P.; Alix, C. Consistent negative temperature sensitivity and positive influence of precipitation on growth of floodplain Picea glauca in Interior Alaska. Can. J. For. Res. 2012, 42, 561-573.

29. Vaganov, E.; Hughes, M.; Kirdyanov, A.; Schweingruber, F.; Silkin, P. Influence of snowfall and melt timing on tree growth in subarctic Eurasia. Nature 1999, 400, 149-151.

30. Barnett, T.P.; Adam, J.C.; Lettenmaier, D.P. Potential impacts of a warming climate on water availability in snow-dominated regions. Nature 2005, 438, 303-309.

31. Welp, L.; Randerson, J.; Liu, H. The sensitivity of carbon fluxes to spring warming and summer drought depends on plant functional type in boreal forest ecosystems. Agric. For. Meteorol. 2007, 147, 172-185.

32. Hu, J.; Moore, D.; Burns, S.; Monson, R. Longer growing seasons lead to less carbon sequestration by a subalpine forest. Glob. Chang. Biol. 2010, 16, 771-783.

33. Trujillo, E.; Molotch, N.P.; Goulden, M.L.; Kelly, A.E.; Bales, R.C. Elevation-dependent influence of snow accumulation on forest greening. Nat. Geosci. 2012, 5, 705-709.

34. Grippa, M.; Kergoat, L.; Le Toan, T.; Mognard, N.; Delbart, N.; L'Hermitte, J.; Vicente-Serrano, S. The impact of snow depth and snowmelt on the vegetation variability over central Siberia. Geophys. Res. Lett. 2005, 32, doi:10.1029/2005GL024286.

35. Buermann, W.; Bikash, P.R.; Jung, M.; Burn, D.H.; Reichstein, M. Earlier springs decrease peak summer productivity in North American boreal forests. Environ. Res. Lett. 2013, 8, 024027.

36. Brown, R.; Robinson, D. Northern Hemisphere spring snow cover variability and change over 1922-2010 including an assessment of uncertainty. Cryosphere 2011, 5, 219-229.

37. Park, H.; Yabuki, H.; Ohata, T. Analysis of satellite and model datasets for variability and trends in Arctic snow extent and depth, 1948-2006. Polar Sci. 2012, 6, 23-37.

38. Gan, T.Y.; Barry, R.G.; Gizaw, M.; Gobena, A.; Rajagopalan, B. Changes in North American snow packs for 1979-2007 detected from the snow water equivalent data of SMMR and SSM/I passive microwave and related climatic factors. J. Geophys. Res.: Atmos. 2013, 118, 7682-7697.

39. Wilmking, M.; Juday, G.P.; Barber, V.A.; Zald, H.S. Recent climate warming forces contrasting growth responses of white spruce at treeline in Alaska through temperature thresholds. Glob. Chang. Biol. 2004, 10, 1724-1736. 
40. Lloyd, A.H.; Bunn, A.G. Responses of the circumpolar boreal forest to 20th century climate variability. Environ. Res. Lett. 2007, 2, 045013.

41. Vicente-Serrano, S.M.; Gouveia, C.; Camarero, J.J.; Beguería, S.; Trigo, R.; López-Moreno, J.I.; Azorín-Molina, C.; Pasho, E.; Lorenzo-Lacruz, J.; Revuelto, J.; et al. Response of vegetation to drought time-scales across global land biomes. Proc. Natl. Acad. Sci. USA 2013, 110, 52-57.

42. Liu, Y.; Dorigo, W.; Parinussa, R.; de Jeu, R.; Wagner, W.; McCabe, M.; Evans, J.; van Dijk, A. Trend-preserving blending of passive and active microwave soil moisture retrievals. Remote Sens. Environ. 2012, 123, 280-297.

43. Van der Schrier, G.; Barichivich, J.; Briffa, K.R.; Jones, P.D. A scPDSI-based global data set of dry and wet spells for 1901-2009. J. Geophys. Res.: Atmos. 2013, 118, 4025-4048.

44. Takala, M.; Luojus, K.; Pulliainen, J.; Derksen, C.; Lemmetyinen, J.; Kärnä, J.P.; Koskinen, J.; Bojkov, B. Estimating northern hemisphere snow water equivalent for climate research through assimilation of space-borne radiometer data and ground-based measurements. Remote Sens. Environ. 2011, 115, 3517-3529.

45. Pinzon, J.; Tucker, C. Revisiting error, precision and uncertainty in NDVI AVHRR data: Development of a consistent NDVI3g time series. Remote Sens. 2013, under review.

46. Friedl, M.; Sulla-Menashe, D.; Tan, B.; Schneider, A.; Ramankutty, N.; Sibley, A.; Huang, X. MODIS Collection 5 global land cover: Algorithm refinements and characterization of new datasets. Remote Sens. Environ. 2010, 114, 168-182.

47. Townshend, J. User Guide for the MODIS Vegetation Continuous Fields product Collection 5 Version 1, 2011. Available online: https://lpdaac.usgs.gov/sites/default/files/public/modis/docs/ VCF_C5_UserGuide_Dec2011.pdf (accessed on 8 January 2013).

48. Harris, I.; Jones, P.D.; Osborn, T.J.; Lister, D.H. Updated high-resolution grids of monthly climatic observations-The CRU TS3. 10 Dataset. Int. J. Climatol. 2013, doi:10.1002/joc.3711.

49. Trenberth, K.E.; Dai, A.; van der Schrier, G.; Jones, P.D.; Barichivich, J.; Briffa, K.R.; Sheffield, J. Global warming and changes in drought. Nat. Clim. Chang. 2014, 4, doi:10.1038/nclimate2067.

50. Schneider, U.; Becker, A.; Finger, P.; Meyer-Christoffer, A.; Ziese, M.; Rudolf, B. GPCC's new land surface precipitation climatology based on quality-controlled in situ data and its role in quantifying the global water cycle. Theor. Appl. Climatol. 2013, 115, 15-40.

51. Rui, H. README Document for Global Land Data Assimilation System Version 2 (GLDAS-2) Products; NASA Goddard Earth Science Data and Information Services Center: Greenbelt, MD, USA, 2011.

52. Myneni, R.B.; Hall, F.G.; Sellers, P.J.; Marshak, A.L. The interpretation of spectral vegetation indexes. IEEE Trans. Geosci. Remote Sens. 1995, 33, 481-486.

53. Huete, A.; Didan, K.; Miura, T.; Rodriguez, E.P.; Gao, X.; Ferreira, L.G. Overview of the radiometric and biophysical performance of the MODIS vegetation indices. Remote Sens. Environ. 2002, 83, 195-213.

54. Wang, D.; Morton, D.; Masek, J.; Wu, A.; Nagol, J.; Xiong, X.; Levy, R.; Vermote, E.; Wolfe, R. Impact of sensor degradation on the MODIS NDVI time series. Remote Sens. Environ. 2012, 119, $55-61$. 
55. Hancock, S.; Baxter, R.; Evans, J.; Huntley, B. Evaluating global snow water equivalent products for testing land surface models. Remote Sens. Environ. 2013, 128, 107-117.

56. Albergel, C.; Rüdiger, C.; Pellarin, T.; Calvet, J.C.; Fritz, N.; Froissard, F.; Suquia, D.; Petitpa, A.; Piguet, B.; Martin, E.; et al. From near-surface to root-zone soil moisture using an exponential filter: An assessment of the method based on in-situ observations and model simulations. Hydrol. Earth Syst. Sci. Discuss. 2008, 12, 1323-1337.

57. Ebisuzaki, W. A method to estimate the statistical significance of a correlation when the data are serially correlated. J. Clim. 1997, 10, 2147-2153.

58. Visser, H.; Molenaar, J. Kalman filter analysis in dendroclimatology. Biometrics 1988, 44, 929-940.

59. Bronaugh, D. zyp: Zhang + Yue-Pilon Trends Package. Available online: http://CRAN.Rproject.org/package=zyp (accessed 29 January 2011).

60. Wilks, D. Statistical Methods in the Atmospheric Sciences, 3rd ed.; Academic Press: Waltham, MA, USA, 2011.

61. Brown, J.; Ferrians, J., Jr.; Heginbottom, J.; Melnikov, E. Circum-Arctic Map of Permafrost and Ground-Ice Conditions; National Snow and Ice Data Center/World Data Center for Glaciology: Boulder, CO, USA, 1998.

62. Solomon, Q.; Manning, C.; Marquis, A.; Tignor, M.; Miller, H.L. Climate Change 2007: The Physical Science Basis; Cambridge University Press: Cambridge, UK, 2007; p. 996.

63. Rawlins, M.A.; Steele, M.; Holland, M.M.; Adam, J.C.; Cherry, J.E.; Francis, J.A.; Groisman, P.Y.; Hinzman, L.D.; Huntington, T.G.; Kane, D.L.; et al. Analysis of the Arctic system for freshwater cycle intensification: Observations and expectations. J. Clim. 2010, 23, 5715-5737.

64. Miralles, D.; van den Berg, M.; Gash, J.; Parinussa, R.; de Jeu, R.; Beck, H.; Holmes, D.; Jimenez, C.; Verhoest, N.; Dorigo, W.; et al. El Nio-La Nia cycle and recent trends in continental evaporation. Nat. Clim. Chang. 2013, doi:10.1038/nclimate2068.

65. Dai, A. Characteristics and trends in various forms of the Palmer Drought Severity Index during 1900-2008. J. Geophys. Res. 2011, 116, doi:10.1029/2010JD015541.

66. Sheffield, J.; Wood, E.F.; Roderick, M.L. Little change in global drought over the past 60 years. Nature 2012, 491, 435-438.

67. Sheffield, J.; Wood, E.F. Characteristics of global and regional drought, 1950-2000: Analysis of soil moisture data from off-line simulation of the terrestrial hydrologic cycle. J. Geophys. Res.: Atmos. 2007, 112, doi:10.1029/2006JD008288.

68. Shabbar, A.; Skinner, W. Summer drought patterns in canada and the relationship to global sea surface temperatures. J. Clim. 2004, 17, 2866-2880.

69. Bonsal, B.; Regier, M. Historical comparison of the 2001/2002 drought in the Canadian Prairies. Clim. Res. 2007, 33, 229-242.

70. Hogg, E.; Wein, R.W. Impacts of drought on forest growth and regeneration following fire in southwestern Yukon, Canada. Can. J. For. Res. 2005, 35, 2141-2150.

71. Wendler, G.; Conner, J.; Moore, B.; Shulski, M.; Stuefer, M. Climatology of Alaskan wildfires with special emphasis on the extreme year of 2004. Theor. Appl. Climatol. 2011, 104, 459-472. 
72. Kogan, F.; Adamenko, T.; Guo, W. Global and regional drought dynamics in the climate warming era. Remote Sens. Lett. 2013, 4, 364-372.

73. Mohammat, A.; Wang, X.; Xu, X.; Peng, L.; Yang, Y.; Zhang, X.; Myneni, R.B.; Piao, S. Drought and spring cooling induced recent decrease in vegetation growth in Inner Asia. Agric. For. Meteorol. 2013, 178-179, 21-30.

74. Sheffield, J.; Wood, E.F. Projected changes in drought occurrence under future global warming from multi-model, multi-scenario, IPCC AR4 simulations. Clim. Dyn. 2008, 31, 79-105.

75. Manabe, S.; Wetherald, R. Large-scale changes of soil wetness induced by an increase in atmospheric carbon dioxide. J. Atmos. Sci. 1987, 44, 1211-1236.

76. Ohta, T.; Maximov, T.C.; Dolman, A.J.; Nakai, T.; van der Molen, M.K.; Kononov, A.V.; Maximov, A.P.; Hiyama, T.; Iijima, Y.; Moors, E.J.; et al. Interannual variation of water balance and summer evapotranspiration in an eastern Siberian larch forest over a 7-year period (1998-2006). Agric. For. Meteorol. 2008, 148, 1941-1953.

77. Sugimoto, A.; Yanagisawa, N.; Naito, D.; Fujita, N.; Maximov, T.C. Importance of permafrost as a source of water for plants in east Siberian taiga. Ecol. Res. 2002, 17, 493-503.

78. Forkel, M.; Thonicke, K.; Beer, C.; Cramer, W.; Bartalev, S.; Schmullius, C. Extreme fire events are related to previous-year surface moisture conditions in permafrost-underlain larch forests of Siberia. Environ. Res. Lett. 2012, 7, doi:10.1088/1748-9326/7/4/044021.

79. Jorgenson, M.T.; Romanovsky, V.; Harden, J.; Shur, Y.; O’Donnell, J.; Schuur, E.A.; Kanevskiy, M.; Marchenko, S. Resilience and vulnerability of permafrost to climate change. Can. J. For. Res. 2010, 40, 1219-1236.

80. Park, H.; Walsh, J.; Fedorov, A.; Sherstiukov, A.; Iijima, Y.; Ohata, T. The influence of climate and hydrological variables on opposite anomaly in active-layer thickness between Eurasian and North American watersheds. Cryosphere 2013, 7, 631-645.

81. Smol, J.P.; Douglas, M.S. Crossing the final ecological threshold in high Arctic ponds. Proc. Natl. Acad. Sci. USA 2007, 104, 12395-12397.

82. Kasischke, E.S.; Turetsky, M.R. Recent changes in the fire regime across the North American boreal region-Spatial and temporal patterns of burning across Canada and Alaska. Geophys. Res. Lett. 2006, 33, doi:10.1029/2006GL025677.

83. Kljun, N.; Black, T.; Griffis, T.; Barr, A.; Gaumont-Guay, D.; Morgenstern, K.; McCaughey, J.; Nesic, Z. Response of net ecosystem productivity of three boreal forest stands to drought. Ecosystems 2006, 9, 1128-1144.

84. Yarie, J. Effects of moisture limitation on tree growth in upland and floodplain forest ecosystems in interior Alaska. For. Ecol. Manag. 2008, 256, 1055-1063.

85. Piao, S.; Friedlingstein, P.; Ciais, P.; Zhou, L.; Chen, A. Effect of climate and $\mathrm{CO}_{2}$ changes on the greening of the Northern Hemisphere over the past two decades. Geophys. Res. Lett. 2006, 33, doi:10.1029/2006GL028205.

86. Alcaraz-Segura, D.; Chuvieco, E.; Epstein, H.E.; Kasischke, E.S.; Trishchenko, A. Debating the greening vs. browning of the North American boreal forest: Differences between satellite datasets. Glob. Chang. Biol. 2010, 16, 760-770. 
87. Wang, X.; Piao, S.; Ciais, P.; Li, J.; Friedlingstein, P.; Koven, C.; Chen, A. Spring temperature change and its implication in the change of vegetation growth in North America from 1982 to 2006. Proc. Natl. Acad. Sci. USA 2011, 108, 1240-1245.

88. Donohue, R.J.; Roderick, M.L.; McVicar, T.R.; Farquhar, G.D. Impact of $\mathrm{CO}_{2}$ fertilization on maximum foliage cover across the globe's warm, arid environments. Geophys. Res. Lett. 2013, 40, 3031-3035.

89. Tape, K.; Sturm, M.; Racine, C. The evidence for shrub expansion in northern Alaska and the Pan-Arctic. Glob. Chang. Biol. 2006, 12, 686-702.

90. Bhatt, U.S.; Walker, D.A.; Raynolds, M.K.; Bieniek, P.A.; Epstein, H.E.; Comiso, J.C.; Pinzon, J.E.; Tucker, C.J.; Polyakov, I.V. Recent declines in warming and vegetation greening trends over Pan-Arctic tundra. Remote Sens. 2013, 5, 4229-4254.

91. Ma, Z.; Peng, C.; Zhu, Q.; Chen, H.; Yu, G.; Li, W.; Zhou, X.; Wang, W.; Zhang, W. Regional drought-induced reduction in the biomass carbon sink of Canada's boreal forests. Proc. Natl. Acad. Sci. USA 2012, 109, 2423-2427.

92. Schaberg, P.G.; Hennon, P.E.; D’amore, D.V.; Hawley, G.J. Influence of simulated snow cover on the cold tolerance and freezing injury of yellow-cedar seedlings. Glob. Chang. Biol. 2008, 14, 1282-1293.

93. Brooks, P.D.; Grogan, P.; Templer, P.H.; Groffman, P.; Öquist, M.G.; Schimel, J. Carbon and nitrogen cycling in snow-covered environments. Geogr. Compass 2011, 5, 682-699.

94. Biancamaria, S.; Cazenave, A.; Mognard, N.M.; Llovel, W.; Frappart, F. Satellite-based high latitude snow volume trend, variability and contribution to sea level over 1989/2006. Glob. Planet. Chang. 2011, 75, 99-107.

95. Callaghan, T.; Johansson, M.; Brown, R.; Groisman, P.; Labba, N.; Radionov, V.; Barry, R.; Bulygina, O.; Essery, R.; Frolov, D.; et al. The changing face of Arctic snow cover: A synthesis of observed and projected changes. AMBIO J. Hum. Environ. 2011, 40, 17-31.

96. Pederson, G.T.; Gray, S.T.; Woodhouse, C.A.; Betancourt, J.L.; Fagre, D.B.; Littell, J.S.; Watson, E.; Luckman, B.H.; Graumlich, L.J. The unusual nature of recent snowpack declines in the North American Cordillera. Science 2011, 333, 332-335.

97. Kantzas, E.; Lomas, M.; Quegan, S.; Zakharova, E. Evaluation of the snow regime in dynamic vegetation land surface models using field measurements. Evaluation 2013, 7, 2333-2372.

98. Wang, T.; Ottl, C.; Boone, A.; Ciais, P.; Brun, E.; Morin, S.; Krinner, G.; Piao, S.; Peng, S. Evaluation of an improved intermediate complexity snow scheme in the ORCHIDEE land surface model. J. Geophys. Res. Atmos. 2013, 118, 6064-6079.

99. Diffenbaugh, N.S.; Scherer, M.; Ashfaq, M. Response of snow-dependent hydrologic extremes to continued global warming. Nat. Clim. Chang. 2012, 3, 379-384. 


\section{Appendix}

Figure A1. Extent of the boreal forest biome and climatologies of soil moisture, NDVI and primary climate variables since 1982. (a) summer satellite microwave soil moisture (MW-SMO, $\mathrm{m}^{3} / \mathrm{m}^{3}$ ) with an overlay of the southern edge of the continuous permafrost (black line); (b) water year (October-September) precipitation from the GPCC dataset v6 (mm); (c) summer mean air temperature from the CRUTS 3.20 dataset $\left(\mathrm{m}^{\circ} \mathrm{C}\right)$; (d) maximum annual Snow Water Equivalent from the GlobSnow product version $1.3(\mathrm{~mm})$; (e) ratio between maximum annual Snow Water Equivalent and water year precipitation; and (f) mean summer NDVI (with non-vegetated areas (NDVI $<0.1$ ) shown in black). The areas north and south of the boreal forest (outlined in gray) correspond to the Arctic and northern temperate regions, respectively. Note that the climatology of the MW-SMO is based on the GLDAS Noah land surface model and is therefore only illustrative of the spatial patterns rather than the absolute values.

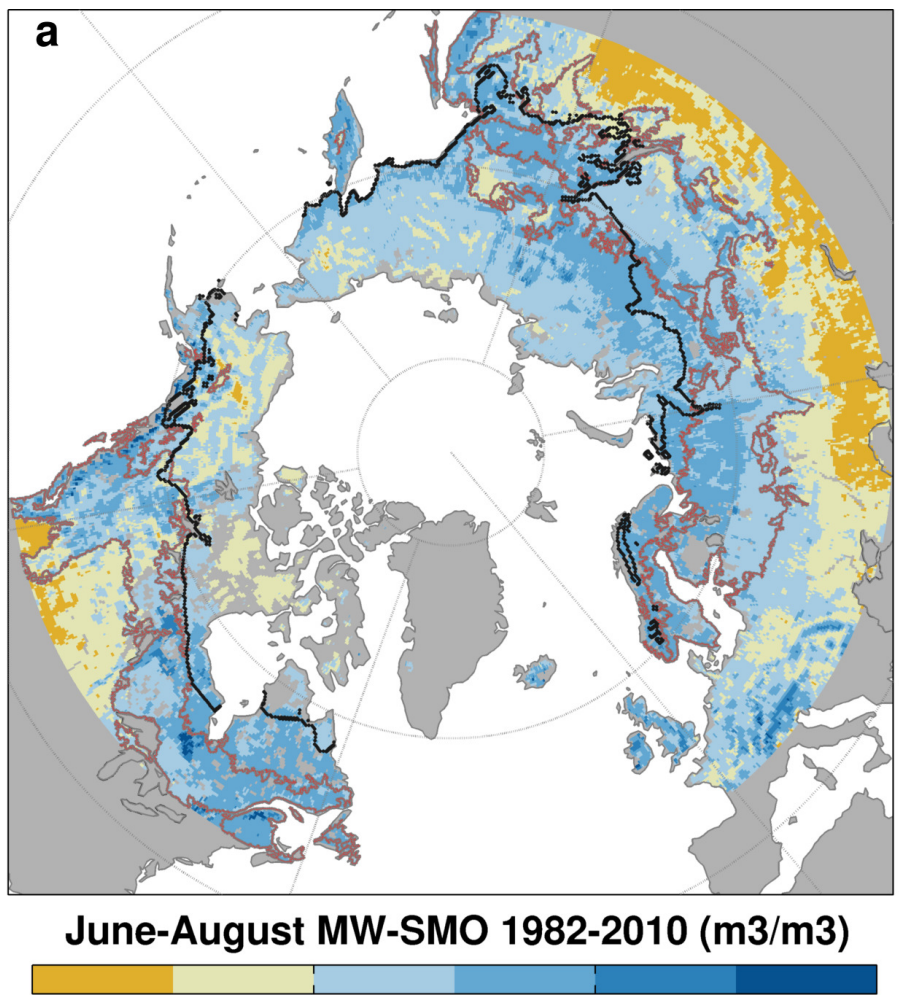

0.1

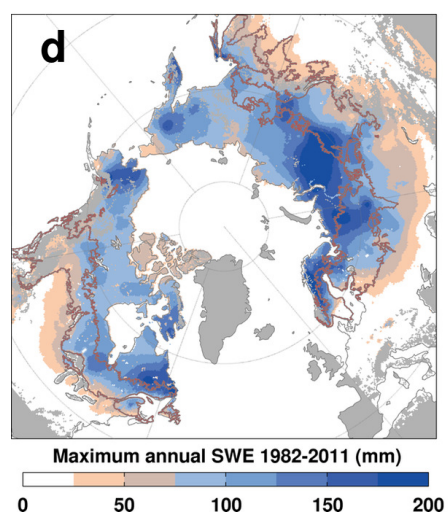

0.3

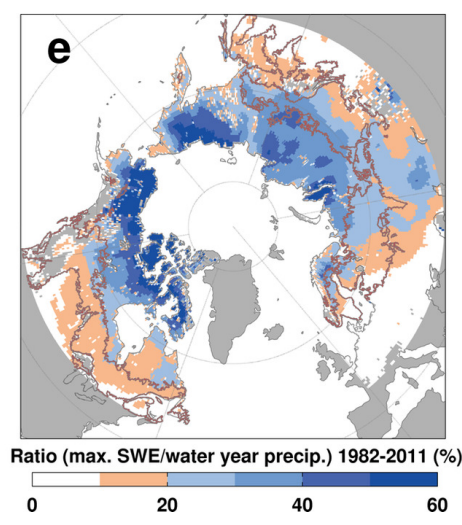

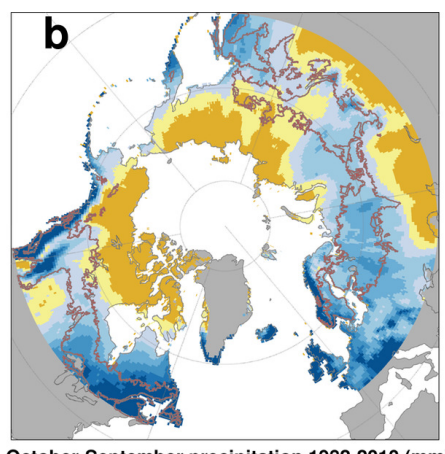

October-September precipitation 1982-2010 (mm) $200 \quad 400 \quad 600 \quad 800 \quad 1000$

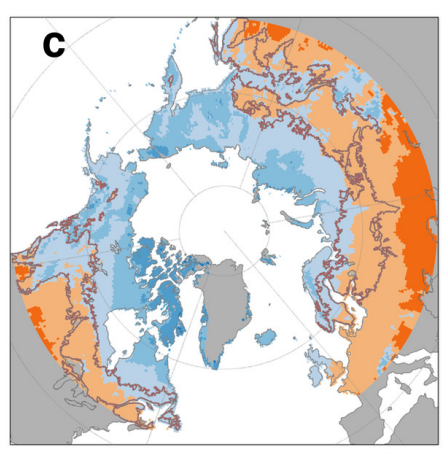

June-August temperature $1982-2011\left({ }^{\circ} \mathrm{C}\right)$
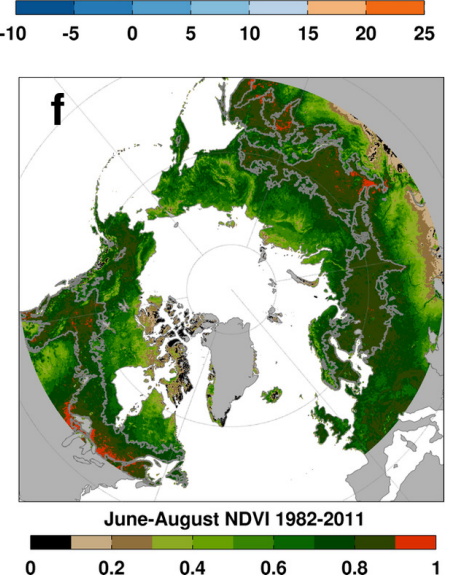
Figure A2. Annual land precipitation anomalies in the Arctic region as represented by different datasets along with their associated temporal and spatial gauge coverage since 1900. The datasets used are: Global Precipitation Climatology Centre (GPCC v6), Climatic Research Unit (CRU TS-3.10.01 and CRU TS-3.21), University of Delaware (UDel v3.02), Global Historical Climatology Network-Monthly (GHCN-M v2) and Global Precipitation Climatology Project (GPCP v2.2). The vertical dotted lines indicate the start of the period of analysis used in this study. The boreal forests are outlined in gray on the map.
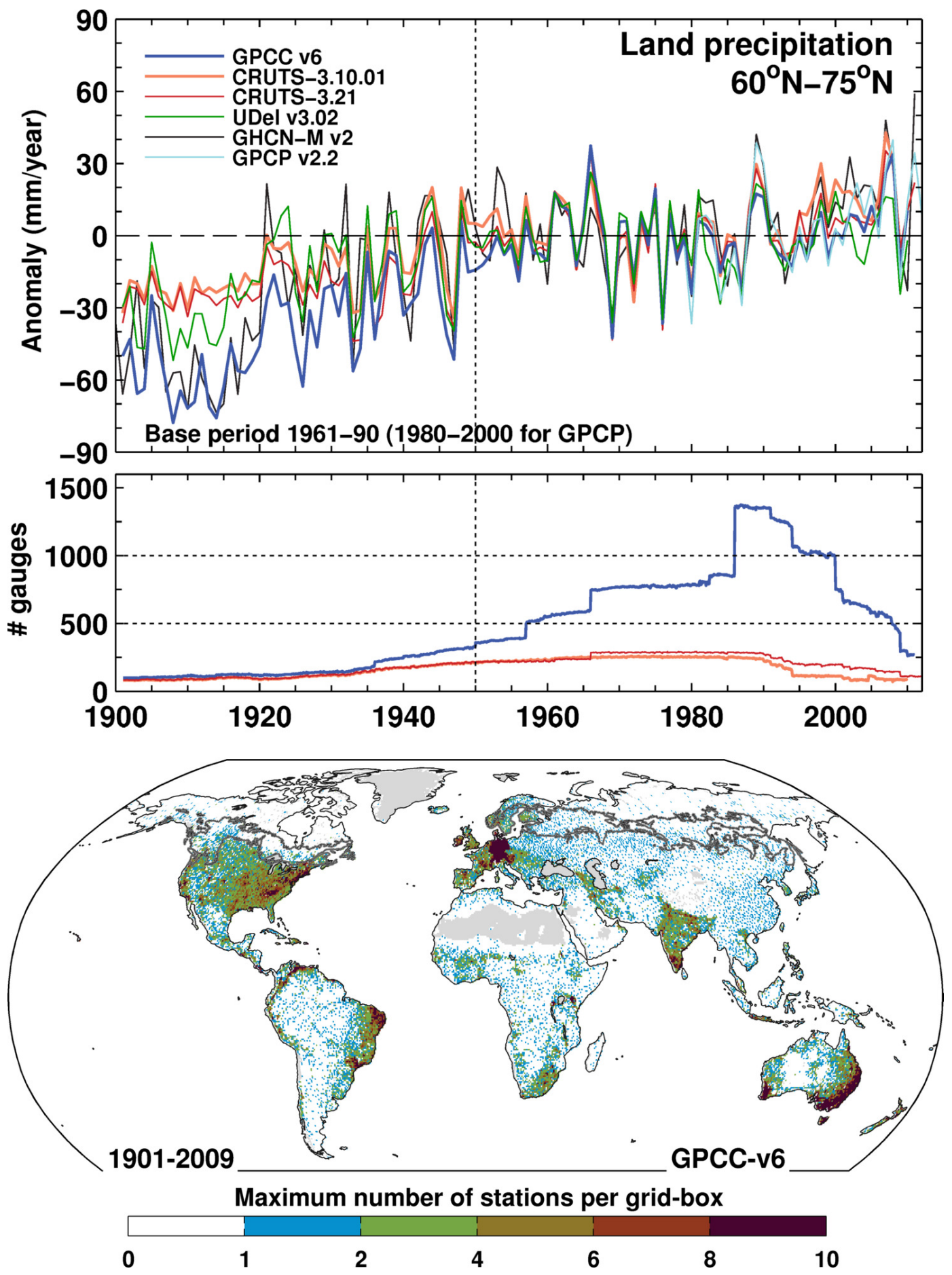
Figure A3. Comparisons of late-spring (April-May) scPDSI averages with (red) and without (blue) changes in potential evapotranspiration and snowmelt by region and continent. Mean April-May temperature anomalies relative to the period 1961-1990 (dotted line) are shown for each region. The vertical dotted lines denote the years 1988 or 1997.
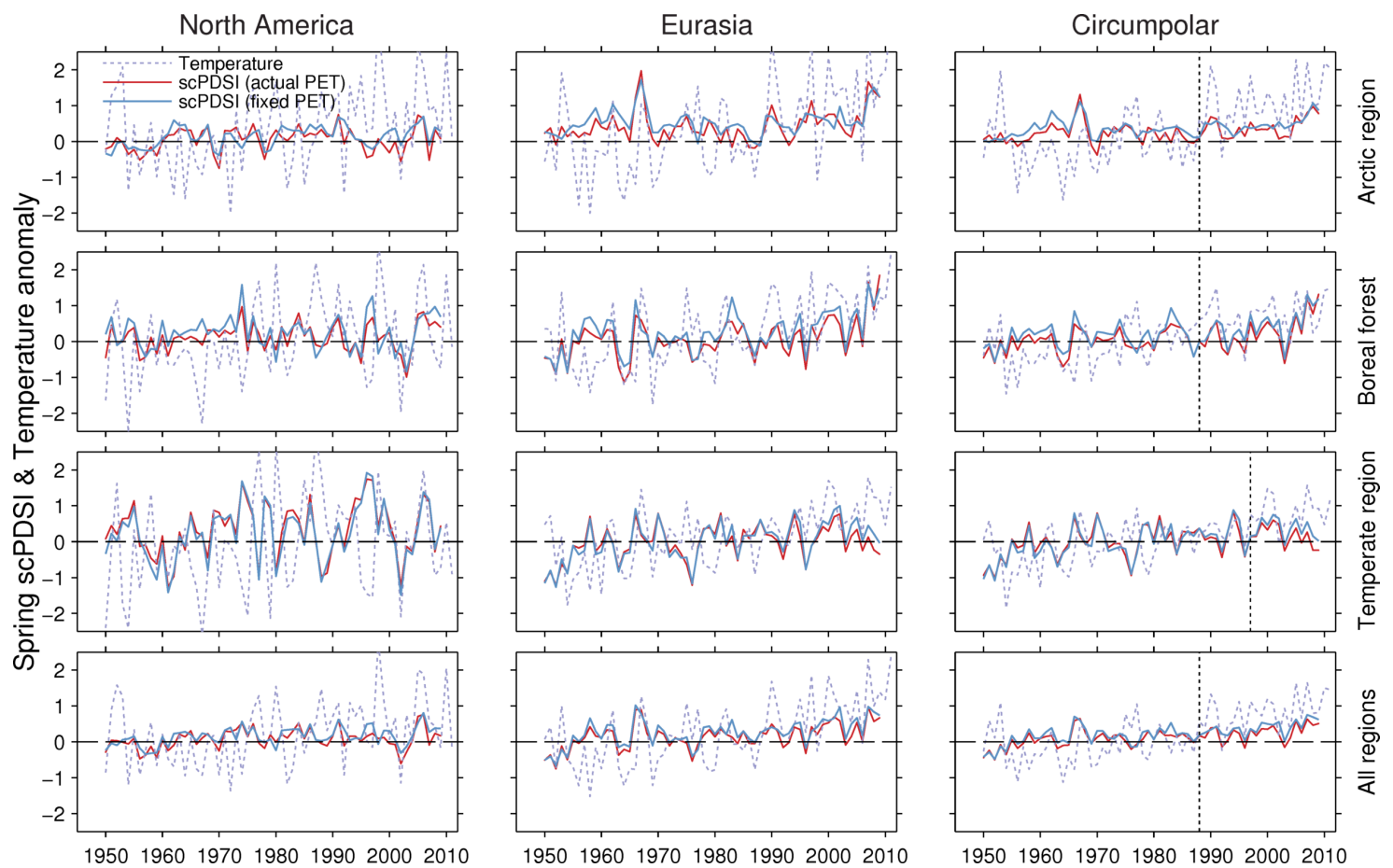

Figure A4. Comparison of average summer scPDSI (blue) and summer 10-cm soil moisture simulated by GLDAS-2 Noah (brown) over the period 1948-2008 for each region and continent. Correlations over the full overlapping period are indicated in each panel (*: $p<0.1)$. Note the good agreement since around 1970.
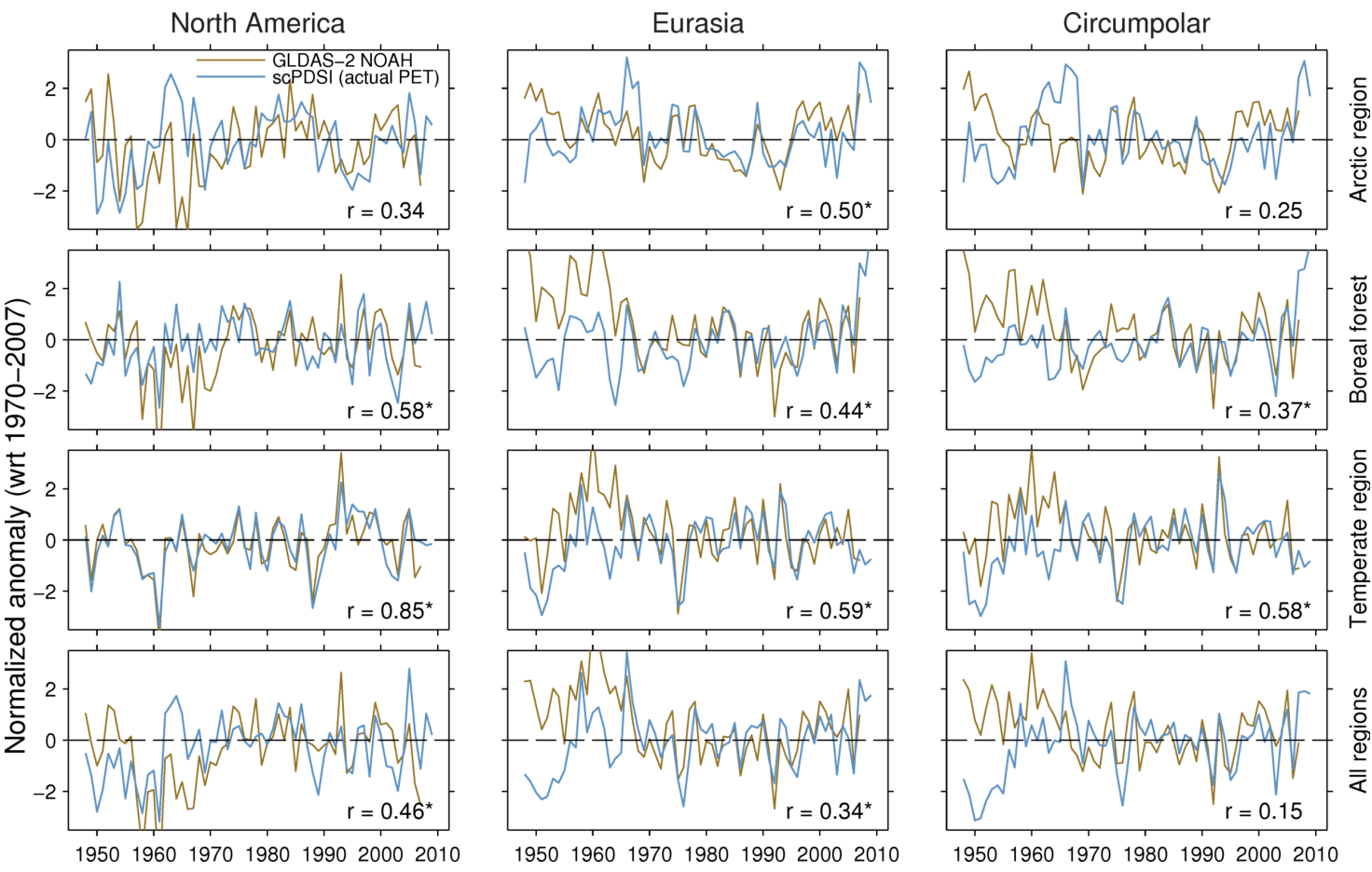
Figure A5. Comparison between summer averages of NDVI3g (green) and Aqua-MODIS NDVI (red) by region and continent during the period 2003-2011.
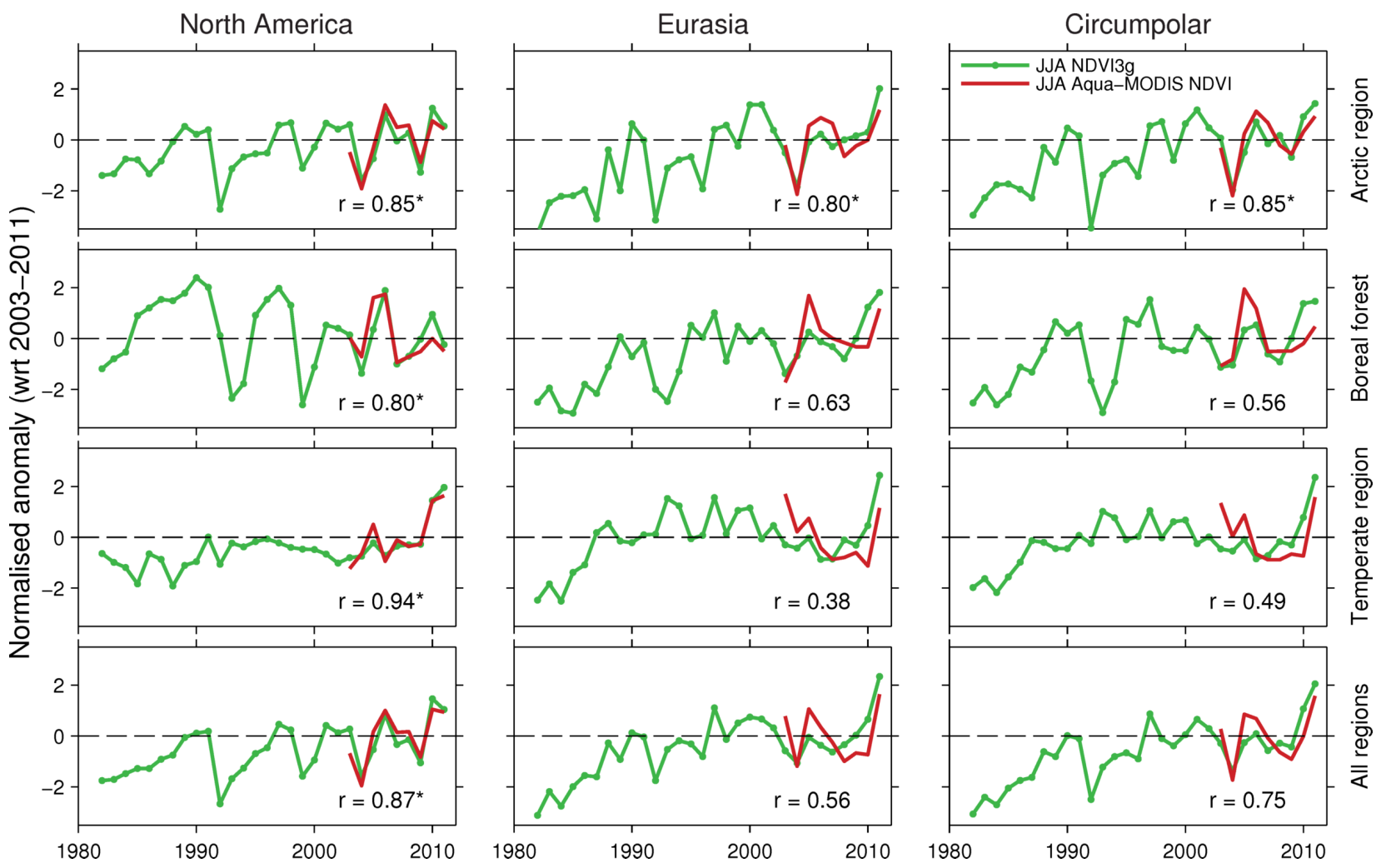
Figure A6. Correlation between linearly detrended climate fields. (a) Correlation of summer precipitation with summer temperature; (b) Correlation of summer precipitation with summer MW-SMO; (c) Correlation between spring scPDSI and maximum SWE; (d) Correlation between summer scPDSI and summer MW-SMO. The stippling indicates statistically significant $(p<0.1)$ correlations.
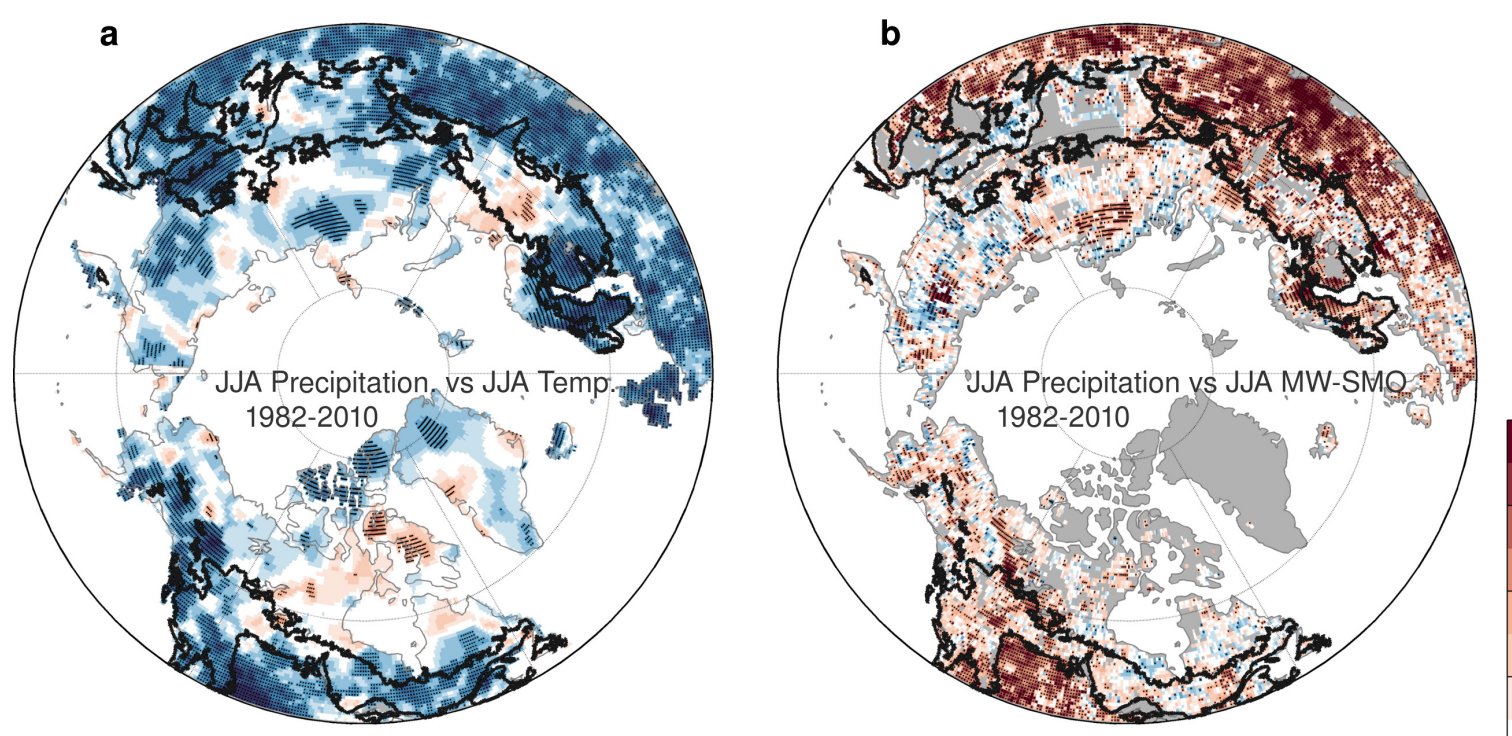

$\begin{array}{ll}0.8 \\ 0.6 \\ 0.4 \\ 0.2 & \frac{}{\frac{\pi}{0}} \\ 0 & \frac{0}{0} \\ -0.2 & 0\end{array}$
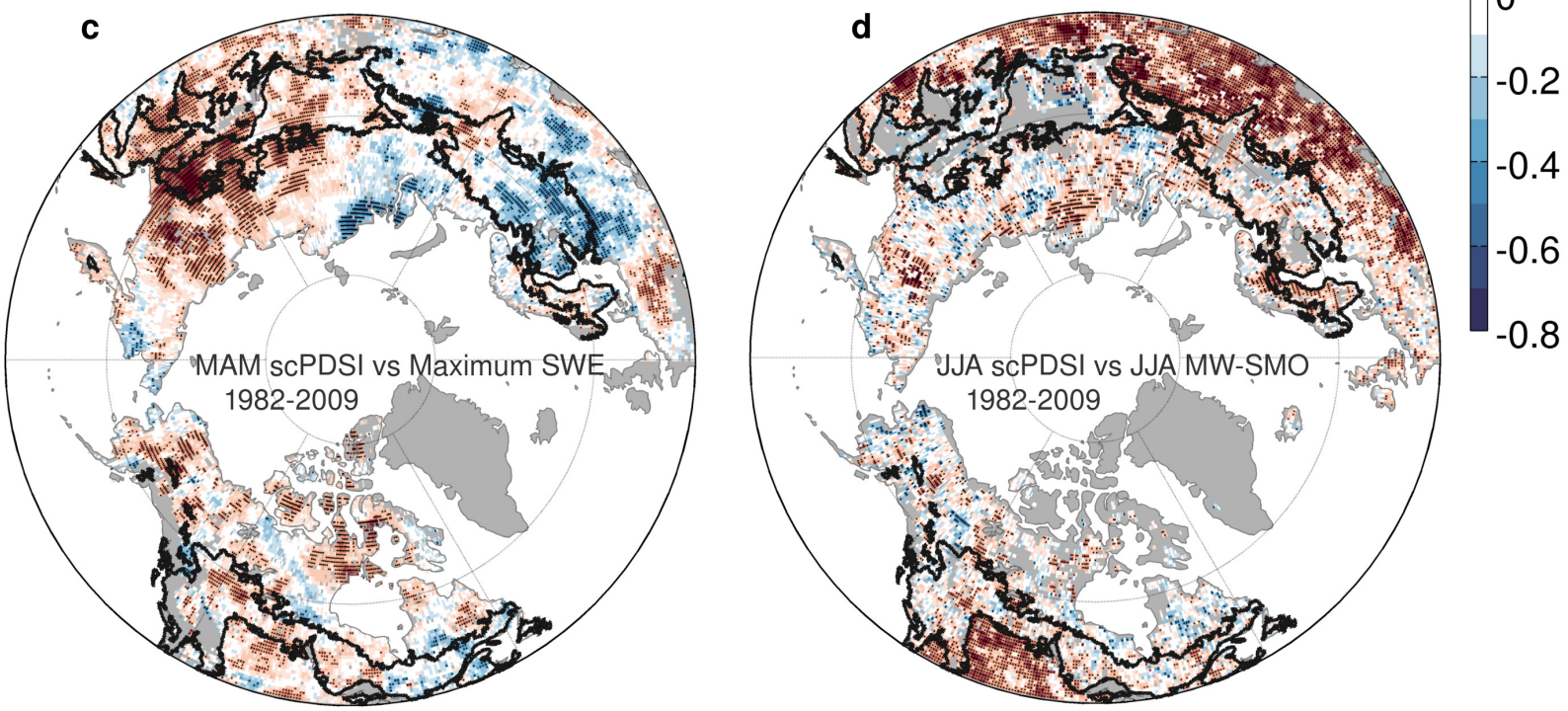

0.4

0.6 
Figure A7. Comparison between maps of climate limitation based on NDVI3g and Aqua-MODIS NDVI during the common period 2002-2009. Each map combines correlations of detrended summer NDVI with detrended summer temperature and scPDSI averaged over spring-summer (March-August). Light greens indicate strong moisture limitation (i.e., strong positive correlation with precipitation and negative correlation with temperature), whilst purple shades indicate a dominant temperature limitation (i.e., strong positive correlation with temperature and weak correlation with precipitation). The stippling indicates grid boxes where either correlations with temperature or scPDSI are statistically significant $(p<0.1)$. Although the significance of these relationships over this very short period is difficult to establish, the spatial patterns are still informative for a comparative purpose. The gray polygons in the maps denote the extent of the boreal forests.
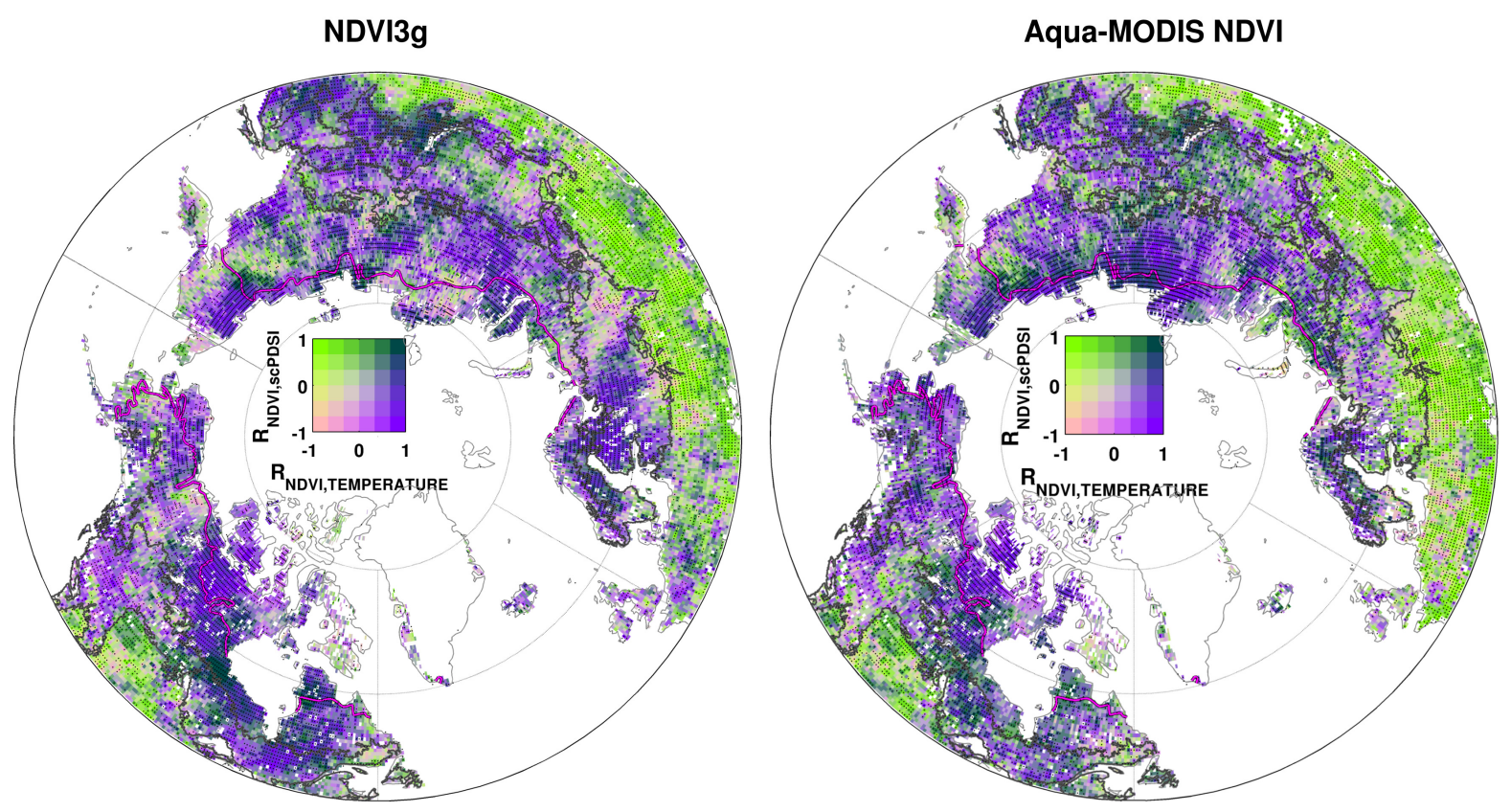

(c) 2014 by the authors; licensee MDPI, Basel, Switzerland. This article is an open access article distributed under the terms and conditions of the Creative Commons Attribution license (http://creativecommons.org/licenses/by/3.0/). 